\title{
Complete genome sequence and phenotype microarray analysis of Cronobacter sakazakii SP291: a persistent isolate cultured from a powdered infant formula production facility
}

\section{Qiongqiong Yan ${ }^{1}$, Karen A. Power ${ }^{1}$, Shane Cooney ${ }^{1}$, Edward Fox ${ }^{1}$, Gopal R. Gopinath ${ }^{2}$, Christopher J. Grim ${ }^{2}$, Ben D. Tall ${ }^{2}$, Matthew P. McCusker ${ }^{1}$ and Séamus Fanning ${ }^{1 *}$}

${ }^{1}$ UCD Centre for Food Safety, WHO Collaborating Centre for Research, Reference and Training on Cronobacter, School of Public Health, Physiotherapy and Population Science, University College Dublin, Dublin, Ireland

2 Division of Virulence Assessment, OARSA, Centre for Food Safety and Applied Nutrition, MOD 1 Facility, Virulence Mechanisms Branch (HFS-025), U.S. Food and Drug Administration, Laurel, MD, USA

\section{Edited by:}

Michael Gänzle, Alberta Veterinary

Research Institute, Canada

Reviewed by:

Stephen Forsythe, Nottingham Trent

University, UK

Lifang Ruan, State Key Lab of

Agricultural Microbiology, China

*Correspondence:

Séamus Fanning, UCD Centre for

Food Safety, UCD Centre for

Molecular Innovation and Drug

Discovery (Science Centre South),

Room S1.04, University College

Dublin, Belfield, Dublin 4, Ireland

e-mail: sfanning@ucd.ie
Outbreaks of human infection linked to the powdered infant formula (PIF) food chain and associated with the bacterium Cronobacter, are of concern to public health. These bacteria are regarded as opportunistic pathogens linked to life-threatening infections predominantly in neonates, with an under developed immune system. Monitoring the microbiological ecology of PIF production sites is an important step in attempting to limit the risk of contamination in the finished food product. Cronobacter species, like other microorganisms can adapt to the production environment. These organisms are known for their desiccation tolerance, a phenotype that can aid their survival in the production site and PIF itself. In evaluating the genome data currently available for Cronobacter species, no sequence information has been published describing a Cronobacter sakazakii isolate found to persist in a PIF production facility. Here we report on the complete genome sequence of one such isolate, Cronobacter sakazakii SP291 along with its phenotypic characteristics. The genome of $C$. sakazakii SP291 consists of a 4.3-Mb chromosome (56.9\% GC) and three plasmids, denoted as pSP291-1, [118.1-kb (57.2\% GC)], pSP291-2, [52.1-kb (49.2\% GC)], and pSP291-3, [4.4-kb (54.0\% GC)]. When C. sakazakii SP291 was compared to the reference C. sakazakii ATCC BAA-894, which is also of PIF origin, the annotated genome data identified two interesting functional categories, comprising of genes related to the bacterial stress response and resistance to antimicrobial and toxic compounds. Using a phenotypic microarray (PM), we provided a full metabolic profile comparing C. sakazakii SP291 and the previously sequenced C. sakazakii ATCC BAA-894. These data extend our understanding of the genome of this important neonatal pathogen and provides further insights into the genotypes associated with features that can contribute to its persistence in the PIF environment.

Keywords: complete genome, plasmid, Cronobacter sakazakii, stress response, antibiotic resistance, toxic compounds

\section{INTRODUCTION}

Cronobacter species (formerly Enterobacter sakazakii) is an opportunistic pathogen of the Enterobacteriaceae family. This organism was originally designated as E. sakazakii in 1980 (Farmer et al., 1980). Based on its recently revised taxonomy, the genus was renamed as Cronobacter in 2007 and now consists of seven species, C. sakazakii, C. malonaticus, C. turicensis, C. muytjensii, C. dublinensis (including three subspecies, dublinensis, lausannensis, and lactaridi), C. universalis and C. condimenti (Iversen et al., 2004, 2007, 2008; Joseph et al., 2011). Infections caused by Cronobacter can present as necrotizing enterocolitis, bacteremia and meningitis, with long term complications for those that survive, including delayed neurological development, hydrocephalus and permanent neurological damage. Life-threatening infections have been reported in neonates (of less than 28 days) (Bar-Oz et al., 2001; Gurtler et al., 2005; Mullane et al., 2007), as well as older infants, with lethality rates ranging between 40 and $80 \%$ (Bowen and Braden, 2006; Friedemann, 2009), and more recently in immunecompromised adults, mainly the elderly (Gosney et al., 2006; See et al., 2007; Hunter et al., 2008; Tsai et al., 2013).

Cronobacter can be isolated from a wide range of foods and environments (Baumgartner et al., 2009; Chap et al., 2009; ElSharoud et al., 2009; Jaradat et al., 2009; Schmid et al., 2009). Specifically, contaminated powdered infant formula (PIF) has been epidemiologically linked with many of the neonatal and infant infections (Himelright et al., 2002; Bowen and Braden, 2006; Mange et al., 2006). Previous studies reported the isolation of Cronobacter from PIF, and the PIF production environment 
(Drudy et al., 2006; Mullane et al., 2008a,b), suggesting that this bacterium has the capacity to adapt to, survive and persist under desiccated environmental conditions. Comparison of environmental and clinical Cronobacter isolates, indicated that the desiccation tolerance exhibited might play a role in the persistence of Cronobacter in PIF and its associated low-moisture ingredients (Walsh et al., 2011; Beuchat et al., 2013). Stress response factors identified previously in Cronobacter, which include heatshock, cold-stresses, survival in dry conditions, water activity $\left(\mathrm{a}_{\mathrm{w}}\right)$, and $\mathrm{pH}$ may contribute to this phenotype (Dancer et al., 2009a,b; Carranza et al., 2010; Chang et al., 2010; Arku et al., 2011). Genome sequencing efforts of Cronobacter species commenced in 2010. To date, 16 genomes are currently available, of which three, C. sakazakii ATCC BAA-894, C. sakazakii ES15 and C. turicensis z3032, are complete (Kucerova et al., 2010; Stephan et al., 2011; Joseph et al., 2012; Shin et al., 2012; Grim et al., 2013).

Following on-going surveillance of a PIF production facility in our laboratory, an interesting isolate $C$. sakazakii SP291 was identified which exhibited a thermo-adapted phenotype when compared with other Cronobacter and Salmonella species tested under laboratory conditions (Cooney, 2012). In an effort to better understand C. sakazakii SP291, its genome was completely sequenced and compared to that of a PIF isolate C. sakazakii ATCC BAA-894, a whole grain isolate C. sakazakii ES15, a clinical isolate C. turicensis z3032 and other selected draft genomes. Additionally, we interrogated the phenome of C. sakazakii SP291, to determine the functionality of strain-specific genotypic traits that may contribute to its adaption capacity in a PIF production environment.

\section{MATERIALS AND METHODS BACTERIAL ISOLATES STUDIED AND THEIR CULTURE CONDITIONS}

Seventeen Cronobacter isolates used in this study are listed in Table 1. Cronobacter sakazakii SP291 was assigned according to the classic rpoB method described previously (Stoop et al., 2009; Lehner et al., 2012). The isolate was cultured routinely in an Isotherm ${ }^{\circledR}$ Forced Convection Laboratory Incubator (Esco GB Ltd., Downton, UK) at $37^{\circ} \mathrm{C}$ on Trypticase Soy Agar (Oxoid Limited, Hampshire, UK) and stored at $-80^{\circ} \mathrm{C}$ on cryo-beads (Technical Service Consultants Ltd., Lancashire, UK).

Table 1 | Cronobacter species, the strain identifier, source, country of origin, and accession numbers.

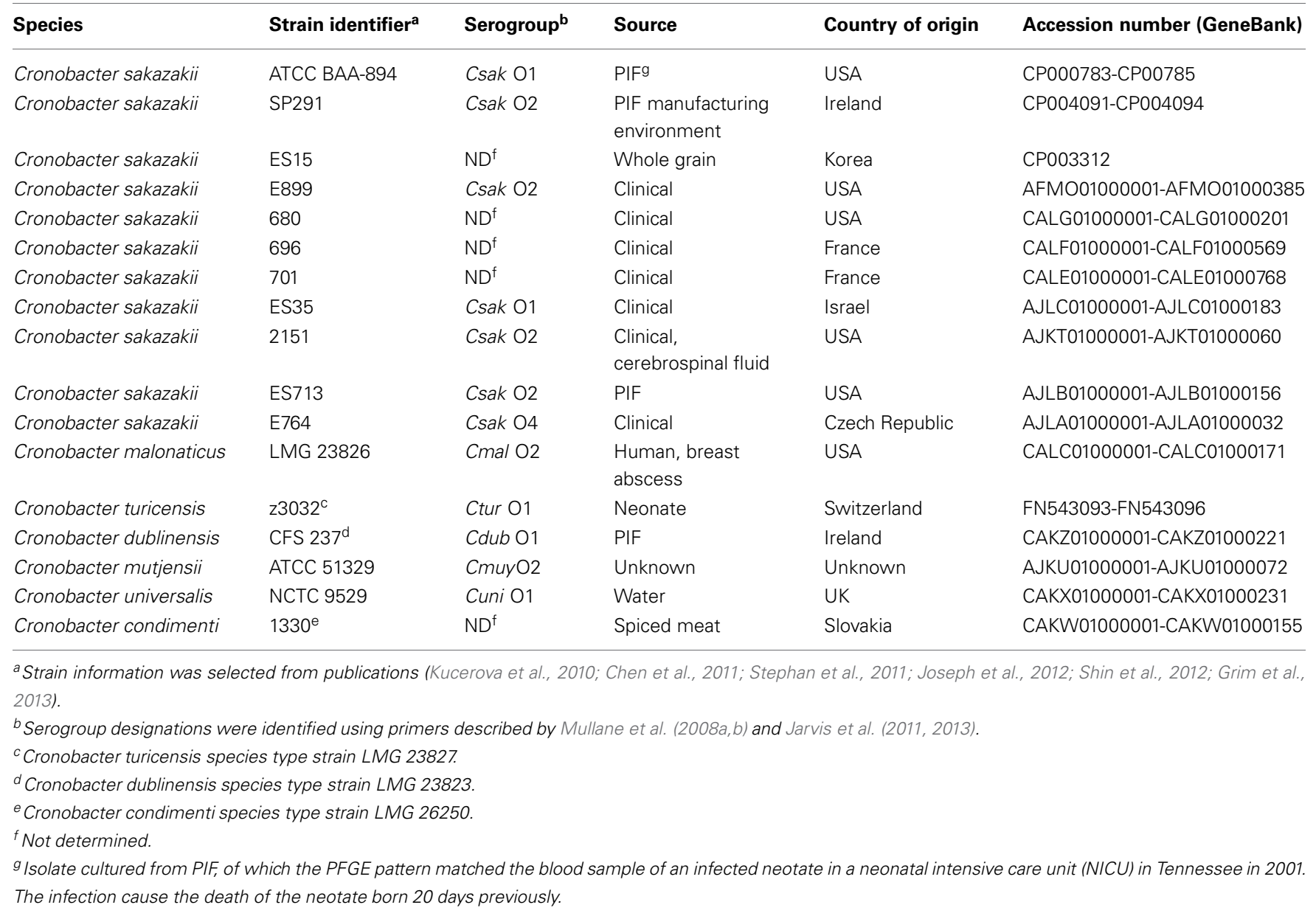




\section{DNA SEOUENCING, ANNOTATION, AND COMPARATIVE GENOMIC ANALYSIS}

Total genomic DNA was purified using a DNeasy Blood and Tissue Kit (QIAGEN, Hilden, Germany) following the manufacturer's instructions. Concentrations were measured using a Nanodrop ${ }^{\circledR}$ (ND 1000) spectrophotometer (Labtech International Ltd., Luton, UK). Purified DNA was maintained at $-20^{\circ} \mathrm{C}$ until required. The whole genome sequencing and assembly methodology is described elsewhere (Power et al., 2013). The complete chromosome and plasmid sequences were uploaded to the RAST (Rapid Annotation using Subsystem Technology) (Aziz et al., 2008) annotation server in a FASTA file format. The RAST server automatically identifies proteinencoding, tRNA and rRNA genes, assigns their functions, predicts the presence of subsystems in the genome, and reconstructs the metabolic network (Aziz et al., 2008). Genome to genome comparative analysis was performed in the SEED viewer as previously reported (Overbeek et al., 2005; Grim et al., 2013). Three complete genomes of C. sakazakii ATCC BAA894 (Accession number CP000783-CP00785), C. sakazakii ES15 (Accession number CP003312) and C. turicensis z3032 (Accession number FN543093-FN543096) were uploaded and annotated in RAST, and used as reference sequences. Most probable insertion or deletion genome regions of C. sakazakii SP291 were identified as previously reported (Grim et al., 2013). In addition, nitrogen metabolism genes, stress-coding genes, as well as antibiotic and toxic compound resistant genes were determined based on significant identity alignments using BLAST. The genome sequence of C. sakazakii SP291 was deposited in GenBank under the accession numbers CP004091-CP004094. The accession numbers for other genome sequences studied were included in Table 1.

\section{PHENOTYPE MICROARRAY ANALYSIS}

Phenotype microarray (PM) analysis was performed on $C$. sakazakii ATCC BAA-894 and C. sakazakii SP291 using the OmniLog ${ }^{\circledR}$ automated incubator/reader (Biolog Inc., Hayward, USA) following manufacturer's instruction. All 20 plates (PM-1 through PM-20) inoculated with bacterial cell suspensions, were incubated at $37^{\circ} \mathrm{C}$ and cell respiration was measured every $15 \mathrm{~min}$ for $48 \mathrm{~h}$. The tetrazolium redox dye is reduced when bacteria respire, which provides both amplification and quantitation of the phenotype. Analysis was carried out using OmniLog ${ }^{\circledR}$ phenotype microarray software v1.2 to determine the phenotypic differences. Negative control wells, which contained the inoculated Omnilog ${ }^{\mathrm{TM}}$ growth medium, but without any substrate, were measured to normalize differences in inocula and redox dye oxidation between samples. The respiration profiles for both strains were compared using PM's integration function software and a significant divergent phenotype was identified when a difference in Omnilog ${ }^{\mathrm{TM}}$ units of $20,000 \pm 1800$ or greater between the two strains was obtained.

\section{RESULTS AND DISCUSSION \\ Cronobacter sakazakii SP291 GENOME}

The complete genome sequence of C. sakazakii SP291 is composed of a single, circular chromosome, $4.34 \mathrm{Mb}$ in length with an average GC content of $56.9 \%$ along with three plasmids (denoted as pSP291-1, 118.136 kb, 57.2\% GC; pSP291-2, $52.134 \mathrm{~kb}, 49.2 \%$ GC and pSP291-3, $4.422 \mathrm{~kb}, 54.0 \%$ GC) (Accession number CP004091-CP004094). The general features of the genome are presented in Table 2. A total of 4129 genes were identified on the chromosome, including 82 tRNA and 22 rRNA genes. The protein coding sequence (CDS) represents $86.3 \%$ of the genome and is organized into $4025 \mathrm{CDS}$, with an average length of 931 nucleic acids (Figure A1). From the annotation of the three plasmids, it was determined that 116 genes cover $87.1 \%$ of pSP291-1, 74 genes cover $77.2 \%$ of pSP291-2 and 7 genes were located on pSP291-3 and accounts for $48.6 \%$ of this structure.

\section{COMPARATIVE GENOMIC ANALYSIS OF C. sakazakii SP291 WITH THREE OTHER COMPLETED Cronobacter GENOMES}

Cronobacter sakazakii SP291 and three other completed genomes: C. sakazakii ATCC BAA-894, C. sakazakii ES15 and C. turicensis z3032 were compared (Figure 1). For the purposes of this comparison, the C. sakazakii ATCC BAA-894 genome was used as the reference. Five genomic regions (denoted as GR-1 through -5 , in Figure 1A) were identified and these were present in the other genomes but missing in C. sakazakii SP291 (Table S1). These GRs are discussed in detail below.

Several unique prophages or phage-like elements of $C$. sakazakii ATCC BAA-894 were noted in GR-1 (genome positions 578,739..601,816), GR-3 (genome positions $2,245,990 \ldots 2,272,660$ ) and GR-4 (genome positions $2,962,630 \ldots 3,022,134)$. Three specific genes were observed in GR-1, which included the DNA-methyltransferase subunit M and the $S$ subunit of a type I restriction-modification system, along with a zinc binding domain/DNA primase, which is a phage P4-associated/replicative helicase denoted as RepA. A lambda phage portal protein, a large subunit of a terminase enzyme, along with some hypothetical proteins were noted in GR-3. In GR-4, a 1478 bp uncharacterized translocase gene required for $\mathrm{O}$-antigen conversion and two-recombination genes, part of the bacteriophage $\operatorname{ninR}$ region, and denoted as $\operatorname{nin} B$ and $\operatorname{nin} G$ were identified. These annotations confirmed those previous reported (Kucerova et al., 2010). Interstingly, a putative bactoprenol

Table 2 | General features of the C. sakazakii SP291 genome.

\begin{tabular}{lllll}
\hline Feature & Chromosome & \multicolumn{3}{c}{ Plasmids } \\
\cline { 3 - 4 } & & pSP291-1 & pSP291-2 & pSP291-3 \\
\hline Size (bp) & $4,344,092$ & 118,136 & 52,134 & 4,422 \\
$\begin{array}{l}\text { Predicted } \\
\text { CDS }\end{array}$ & 4025 & 116 & 74 & 7 \\
$\begin{array}{l}\text { GC content } \\
\text { (\%) }\end{array}$ & 56.9 & & & \\
$\begin{array}{l}\text { Coding } \\
\text { regions (\%) }\end{array}$ & 86.3 & 57.2 & 49.2 & 54.0 \\
$\begin{array}{l}\text { Average } \\
\text { CDS length }\end{array}$ & 931 & 87.1 & 77.2 & 48.6 \\
$\begin{array}{l}\text { (bp) } \\
\text { tRNA }\end{array}$ & & 887 & 544 & 307 \\
rRNA & 82 & & & \\
& 22 & nil & nil & nil \\
& & nil & nil & nil
\end{tabular}




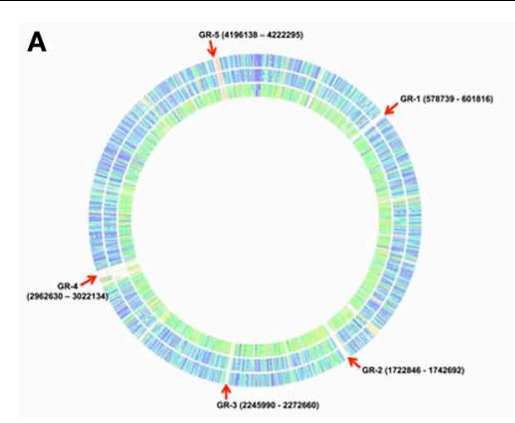

FIGURE 1 | Genomic regions of $C$. sakazakii SP291 compared to three completed genomes consists of $C$. sakazakii ATCC BAA 894, C. sakazakii ES15, and $\boldsymbol{C}$. turicensis z3032. (A) Regions absent in the genome of $C$. sakazakii SP291 compared to the other three genomes. Reference genome: C. sakazakii ATCC BAA-894; Outer circle: C. sakazakii ES15; Middle circle: C.

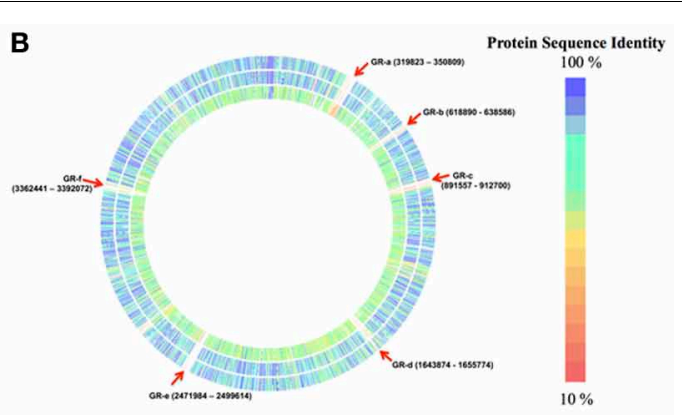

sakazakii SP291; Inner circle: C. turicensis z3032, see also Table S1. (B) Regions present in the genome of $C$. sakazakii SP291 compared to the other three genomes. Reference genome: C. sakazakii SP291; Outer circle: C. sakazakii ATCC BAA-894; Middle circle: C. sakazakii ES15; Inner circle: C. turicensis z3032, see also Table S2. glucosyl transferase was identified in C. sakazakii ATCC BAA894, and shared with C. sakazakii ES15 and C. turicensis z3032, but not C. sakazakii SP291. Regulatory protein CII along with a phage Kil protein were annotated in C. sakazakii ATCC BAA-894 but not C. sakazakii SP291. Although protein CII was absent in $C$. turicensis z3032, the Kil protein was present (Stephan et al., 2011). A recently sequenced phage denoted as, phiES15, contained cII and kil (Lee et al., 2012). Unique transposon genes were noted in GR-2 (genome positions $1,722,846 \ldots 1,742,692$ ) and GR-5 (genome positions 4,196,138 . .4,222,295). In GR-2, a large part of the region containing tellurium resistance-encoding genes, including ter $X$, ter $W$, ter $A$, ter $B, \operatorname{ter} C$, and ter $D$, were identified, a feature reported previously (Kucerova et al., 2010; Joseph et al., 2012; Grim et al., 2013). GR-5 contained heavy metal efflux and resistance genes, which consists of cusS, cusR, cusC, cusF, $c z c B$, $c z c A, c u s A, \operatorname{cop} G, p c o S, p c o B$, and pcoA (Kucerova et al., 2010; Joseph et al., 2012). Further detailed information related to the corresponding phenotypes is outlined below (see also Table S1).

Genes unique to $C$. sakazakii SP291 were also noted and these were used as a reference to interrogate the genomes of the other strains. Six genomic regions (Figure 1B, denoted as GR-a through - $f$, Table S2) were identified as being unique to C. sakazakii SP291. GR-a (genome regions 319,823. . 350,809), GR-d (genome regions 1,643,874. . 165,774) and GR-e (genome regions $2,471,984 \ldots 2,499,614)$ contained a set of phage- and phage-related proteins along with some hypothetical proteins. A phage regulatory CII-like protein was identified in C. sakazakii SP291 and mapped within GR-a, which also matched a similar homolog observed in C. turicensis z3032. A holin protein, which controls the length of an infective cycle for bacteriophage (Wang et al., 2000), together with membrane proteins related to metalloendopeptidases were present in C. sakazakii SP291 alone, being located in GR-e. In GR-b (genome regions 618,890 . .638,586), a YkfI toxin-encoding protein along a YfjZ-antitoxin encoding protein (the corresponding antitoxin to YpjF) were identified and unique to C. sakazakii SP291. This toxin-antitoxin protein pair was also reported in E. coli previously and was shown to regulate cell death through the disruption of essential cellular processes (Brown and Shaw, 2003). It has been proposed by Lewis
(2000) that, under some circumstances, it may be evolutionarily advantageous for some cells in a population to undergo programmed cell death in order to provide nutrients for the remainder. Toxin-antitoxin pairs were noted in a previous study as most Cronobacter genomes contain a large number of them, which might be conserved, shared, or unique (Grim et al., 2013). GR-c (genome regions 891,557. . 912,700) contains seven interesting genes, which includes an uncharacterized protein YeeT, a NgrB protein, an ATP-dependent Clp protease, an ATP-binding subunit $\mathrm{ClpA}$, a small HspC2 heat shock protein, a galactoside Oacetyltransferase-encoding gene and an anti-restriction protein KlcA which have been reported as a component part of a type I DNA restriction system (Serfiotis-Mitsa et al., 2010). A helicase protein, a glycerol dehydrogenase enzyme-encoding gene, and a DNA-cytosine methyltransferase were identified within GR-f (genome regions 3,363,441..3,392,072). Of note, a type I restriction-modification system, specificity the S-subunit-like gene, was identified in C. sakazakii SP291, a feature which was noted earlier in C. sakazakii ATCC BAA-894 (Kucerova et al., 2010; Joseph et al., 2012).

\section{COMPARATIVE GENOMIC ANALYSIS OF C. sakazakii SP291 AND SELECTED AVAILABLE GENOMES WITHIN THIS GENUS}

Two earlier studies described the core genome of Cronobacter (Joseph et al., 2012; Grim et al., 2013). The availability of C. sakazakii SP291 genome has provided an opportunity to reevaluate the content of the Cronobacter core gemome, comparing it to other currently available genome sequences within the genus. Thus, a comparison between C. sakazakii SP291 and 16 other Cronobacer genomes (Table 1) was performed in SEED viewer server.

Within the 11 Cronobacter sakazakii isolates compared, 57 annotated genes were present in C. sakazakii SP291, but absent in all other genomes, including 41 hypothetical proteins, 12 phage- and prophage-related genes/proteins and four other genes/proteins (Table S3). Among all seven Cronobacter species, there were 154 annotated genes/proteins absent in other species, including 122 hypothetical proteins, 4 phage- and prophagerelated genes/proteins and 28 unique genes/proteins (Table S4). 
Interestingly, a conserved domain protein was identified that was unique to $C$. sakazakii SP291, which is associated with retron-type reverse transcriptase. Fifteen genes were shared with other species by C. sakazakii SP291, but were absent in all the C. sakazakii genomes compared to date, and these consisted of a retron-type RNA-directed DNA polymerase, a holin protein which controls the timing of bacteriophage infections as mentioned earlier, a topoisomerase IA-encoding protein, and 12 phage- and prophage-related proteins. There were 31 proteins, which are only shared with some of the C. sakazakii genomes by C. sakazakii SP291 and which were absent among the other six species. These included a sodium-dependent phosphate transporter protein, a RelE antibacterial toxin protein, a RelB protein (antitoxin to RelE), a probable poly (beta-D-mannuronate) $\mathrm{O}$-acetylase protein, two putative periplasmic proteins, a possible secretory protein, a GTPase protein, denoted as NgrB, a mobile element protein, a galactoside $\mathrm{O}$-acetyltransferase protein, a mannose-6-phosphate isomerase, class I protein, a different locus type I restriction-modification system, specificity the $S$ subunit-like protein, a predicted transcriptional regulator COGs COG2378, permeases of the major facilitator superfamily, a superfamily II DNA/RNA helicases, SNF2 family, a DNA modification methylase, an IS1 transposase OrfA protein, a probable tonB-dependent receptor $y n c D$ precursor, a putative ORF-4 protein, a putative ORF (located using Glimmer/Genemark), seven beta-fimbriae probable major subunits, and four phage related proteins.

\section{ANNOTATED PLASMIDS CONTAINED IN C. sakazakii SP291}

Cronobacter sakazakii SP291 contains three plasmids, including pSP291-1, 118,136 bp (57.2\% GC), pSP291-2, 52,134 bp (49.2\%) and pSP291-3, 4,422 bp (54.0\% GC). The predicted CDS of pSP291-1 was found to be 116, with the average length of $887 \mathrm{bp}$, while pSP291-2 has 74 CDS with an average length of $544 \mathrm{bp}$, and pSP291-3 has seven CDS and with the average length of $307 \mathrm{bp}$ (Table 2). Comparision of all three plasmids with five previously published plasmid sequences (including pESA2 and pESA3 of C. sakazakii ATCC BAA-894; along with pCTU1, pCTU2, and pCTU3 of C. turicensis z3032) indicated two closely related plasmid groups. Plasmid group 1, contains pSP291-1, pESA3, and pCTU1, while plasmid group 2, consists of pSP291-2 and pCTU3 (Figures A2, A3, and Table S5).

Several common genes were identified in plasmid group 1, These consisted of a complete ABC transporter (which could function to transport iron; vitamin B12; siderophores and hemin), including the ATP-binding component, the periplasmic substrate-binding module and the permease element. These genes were identified in all three plasmids. An aerobactin siderophore receptor (the IutA/TonB-dependent siderophore receptor) was shared between the three plasmids, while a Cronobacter plasminogen activator ( $c p a)$ homolog has only been mapped to pESA3 and pSP291-1, but not pCTU1, which is in agreement with the results reported by Franco et al. (2011) and Grim et al. (2012) (Figure A2). Three arsenical resistance genes were identified on all three plasmids along with pCTU3. Genes corresponding to commonly shared proteins on all three plasmids included a C-terminal helicase protein, a HipA protein previously reported to be required for growth arrest and multi-drug resistance in Escherichia coli (Correia et al., 2006), a hypothetical-encoding gene $y c g F$ reported to be a direct anti-repressor which acts in the blue-light response of $E$. coli (Tschowri et al., 2009), a starvation sensing protein RspA, a magnesium transporting P-type 1 ATPase protein, transcriptional regulators, including members of ArsR family, GntR family (Kucerova et al., 2010; Joseph et al., 2012), LysR family and TetR-family, a MFS superfamily transporter, a Trk system encoding the potassium uptake protein TrkG, and an uncharacterized protein ImpD. A two-component response regulator protein, a two-component system sensor protein, three uncharacterized proteins $\operatorname{ImpB}$, ImpC, and ImpJ/VasE, a glutathione S-transferase protein, a membrane protein, suppressor for copper-sensitivity ScsB, a hypothetical ABC transport system, periplasmic component, a RND efflux transporter, a suppression of copper sensitivity: putative copper binding protein ScsA were shared between pSP291-1 and pESA3, but not pCTU1, which confirmed the findings from previous studies (Kucerova et al., 2010; Joseph et al., 2012). In plasmid group 2, 15 heavy metal (copper, cobalt, zinc, cadmium, lead, and mercury) resistance genes were shared by both plasmids (Figure A3). An osmosensitive $\mathrm{K}^{+}$channel histidine kinase protein $(\mathrm{KdpD})$, and a virulenceassociated protein $v a g C$ were also present in both plasmids. PCR analysis confirmed the presence of a pCTU3 IncH1-like origin of replication gene, repA in C. sakazakii SP291 (data not shown).

Interestingly, pSP291-1 contained two unique proteins, a histone acetyltransferase HPA2 and related acetyltransferases protein, along with an uncharacterized protein ImpH/VasB. Six specific proteins were found in pSP291-2, which included a putative glutathione S-transferase protein, a LysR family transcriptional regulator, a putative phage-associated acyl carrier protein, a Sadenosylmethionine: tRNA ribosyltransferase-isomerase protein, permeases of the major facilitator superfamily and an abortive infection protein. Various pSP291-3 proteins including mobilization proteins MobB, MobC, MobD, and DNA relaxase MbeA, which were not shared with any of the other plasmids, were also identified.

\section{COMPARATIVE PHENOTYPIC PROFILING OF C. sakazakii ATCC BAA-894 AND SP291}

The phenotypic microarray (PM) platform was used previously to support the re-classification of this bacterial genus (Iversen et al., 2008). By comparing the phenotypes of C. sakazakii ATCC BAA-894 and C. sakazakii SP291 expressed across the complete array, interesting differences were observed and these were subsequently assessed in light of comparisons made at the genome level despite of the same PIF orgin. General differences, noted in the phenotypes between the two strains were described in the form of a heat map shown in Figure 2 (the corresponding numerical data is shown in Table S6). Phenotypic differences based on the bacteria's ability to utilize carbon, nitrogen, phosphorous and sulfur sources, as well as other nutrient supplements were noted. Furthermore, growth responses to osmolytes and different $\mathrm{pH}$ growth environments, as measured by the array were also observed for both strains. Antibiotic resistance patterns and the ability to respire in the presence of toxic compounds differed. 


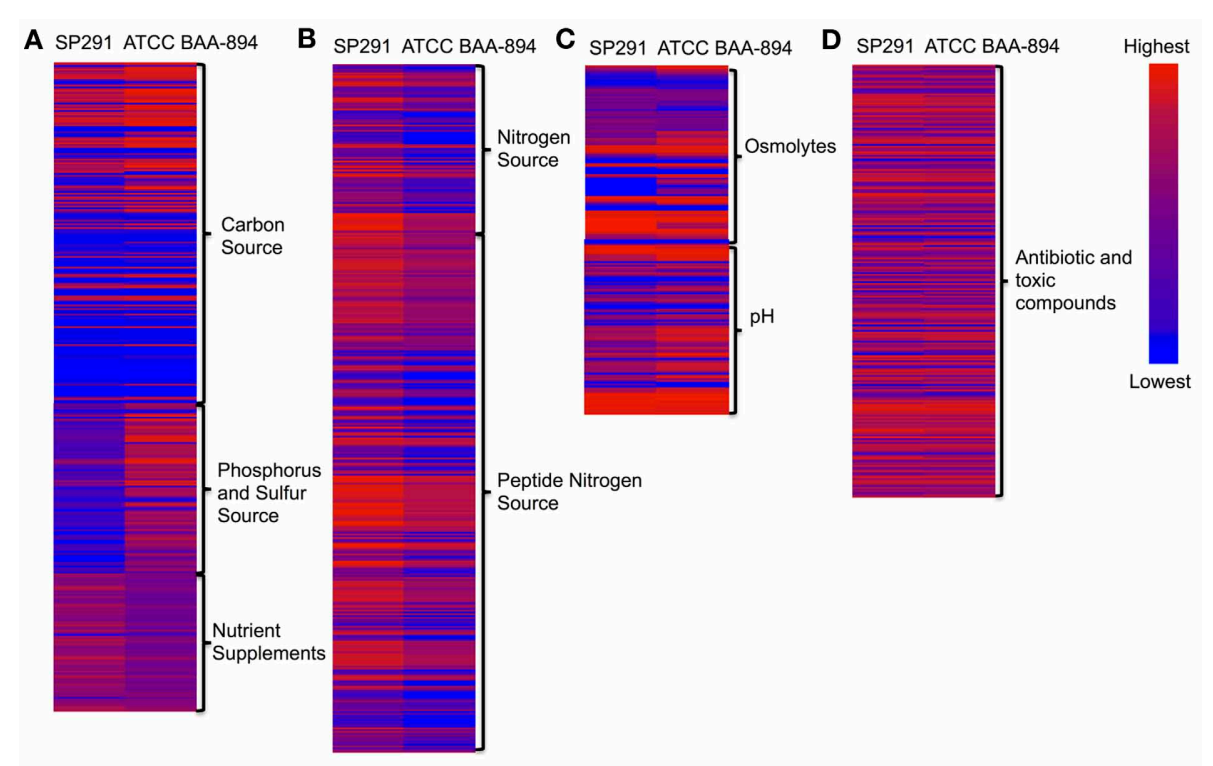

FIGURE 2 | (A-D) Heat map of phenotype microarray (PM). Left lane, C. sakazakii SP291; Right lane, C. sakazakii ATCC BAA-894.

\section{Carbon, nitrogen, phosphorous, and sulfur, other nutrient supplement metabolite utilization}

Bacteria require a sufficient supply of various biomolecules to support their metabolic activity. In natural environments, where these bacteria are often found, it is to be expected that only limited amounts of these nutrients may be available. To support efficient adaptation and to enable growth in these conditions, bacteria will evolve redundant metabolic systems to support the utilization of a broad range of different substrates, with varying efficiencies. The PM array data gives an insight into how these features differ, between C. sakazakii SP291 and C. sakazakii ATCC BAA-894.

A number of phenotypic differences based on their ability to utilize a range of carbon sources were noted (Figure $2 \mathrm{~A}$ and Table S6). When compared with C. sakazakii ATCC BAA-894, C. sakazakii SP291 could grow faster in m-inositol and slower in succinic acid, dulcitol, D,L- $\alpha$-glycerol phosphate, D,L-malic acid, Tween 20, $\alpha$-ketoglutaric acid, uridine, bromosuccinic acid, glycolic acid, inosine, and dextrin. In contrast there were little or no differences in growth rates when other carbon sources such as methyl pyruvate, mannose, and $\beta$-methyl-D-glucuronic acid were compared.

Differences in phenotypes based on the metabolism of carbon sources were compared at the genome level within the carbohydrate subsystem (Table S7). Interestingly, nine inositol catabolism genes were annotated in the C. sakazakii SP291 genome (Table S8), which supported the PM data. Furthermore, a pentose phosphate pathway gene, a lactose utilization gene, and a sucrose utilization gene were also annotated in the C. sakazakii SP291 genome specifically although no evidence to support their activity was found following PM analysis. Similarly, a maltose and maltodextrin utilization gene and a lactate utilization gene were annotated in C. sakazakii ATCC BAA-894 alone, with supporting evidence for the activity lacking from the PM array data. In all, 428 annotated genes related to carbon metabolism were shared between C. sakazakii ATCC BAA-894 and C. sakazakii SP291, which included 10 chitin and $\mathrm{N}$-acetylglucosamine utilization genes, five fructoselysine (amadori product) utilization pathway genes, five dehydrogenase complexes genes, a dihydroxyacetone kinases gene, 14 Entner-Doudoroff pathway genes, and others.

Dancer et al. (2009a,b) reported that for Cronobacter species the availability and utilization of a nitrogen source was an important determinant for biofilm formation when growing in skim milk, and that strong biofilm formers were responsible for coagulation of skim milk (Dancer et al., 2009a). Data from the phenotypic microarray, showed no differences in nitrogen metabolism when C. sakazakii ATCC BAA-894 and C. sakazakii SP291 were compared (Figure 2B and Table S6). Interestingly, when regions of these two genomes known to encode genes associated with nitrogen metabolism were compared, a 16-kb locus, consisting of eight genes was found to be absent in C. sakazakii SP291 compared to C. sakazakii ATCC BAA-894 (Table 3). BLAST analysis of the region facilitated the identification of the corresponding genes located at this position. This locus, contained two nitrate transport proteins $\mathrm{NrtB}$ and NrtC, two nitrite reductase proteins NasB and NasA, a respiratory nitrate reductase NarL, a nitrate/nitrite-sensing protein NarX, a nitrite extrusion protein 1 NarK, and a nitrate reductase 1, alpha subunit NarG. This region was also present in C. sakazakii ES15 and C. turicensis z3032. Furthermore, 24 nitrate genes were broadly shared between both of the genomes, which was supported by data from the PM analysis.

C. sakazakii SP291 was found to grow significantly slower in minimal media supplemented with phosphorous containing compounds (Figure 2A and Table S6), particularly in O-phospho-D-tyrosine, phospho-L-arginine, D,L- $\alpha$-glycerol 
Table 3 | Genes associated with nitrogen metabolism, comparing C. sakazakii SP291 and C. sakazakii ATCC BAA 894.

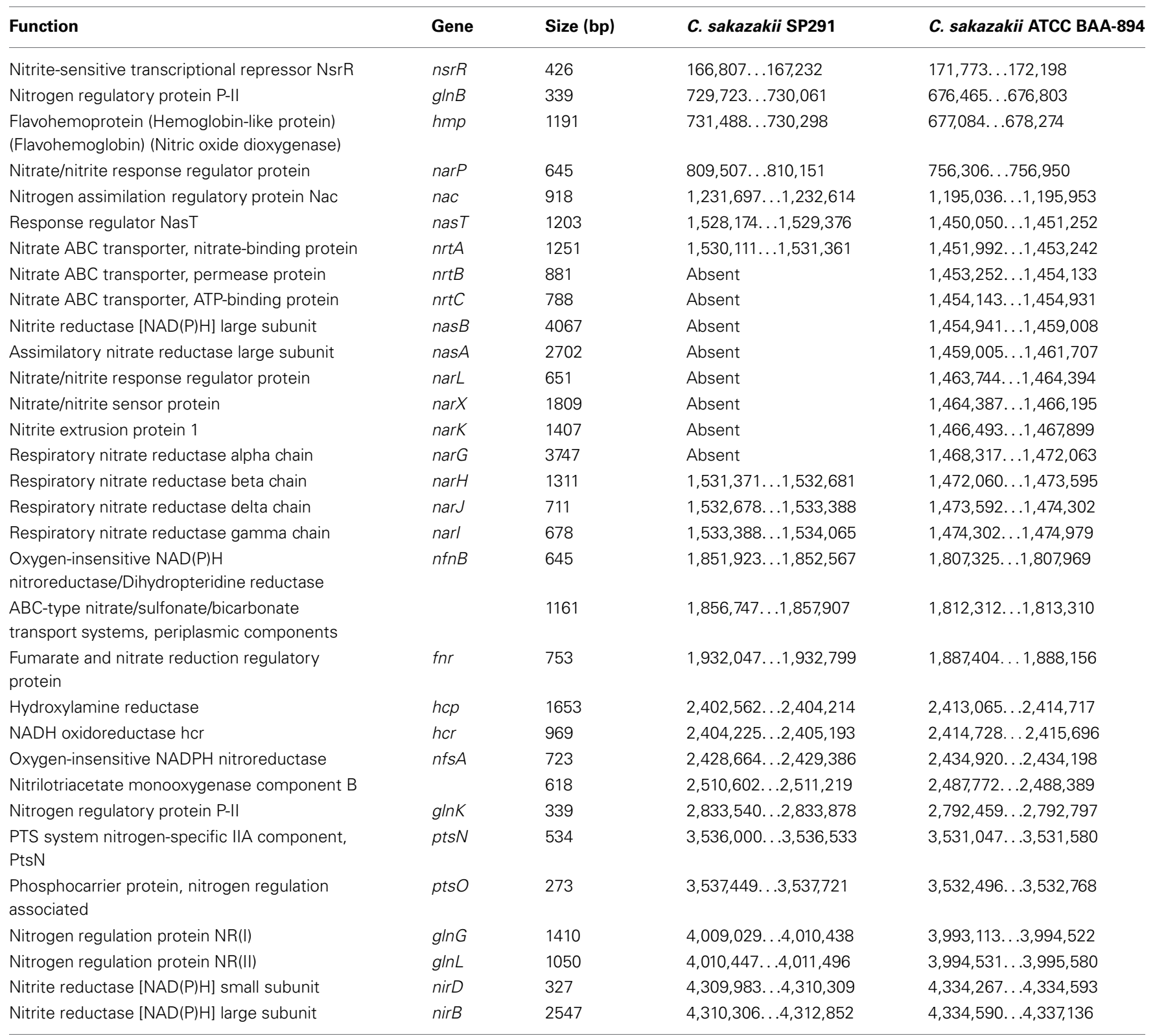

phosphate, $\beta$-glycerol phosphate, phosphoryl choline, phosphoenol pyruvate, D-glucose-6-phosphate, adenosine $3^{\prime}$-monophosphate, guanosine $2^{\prime}$-monophosphate, guanosine $3^{\prime}$-monophosphate, guanosine $5^{\prime}$-monophosphate, guanosine $2^{\prime}, 3^{\prime}$-cyclic monophosphate, cytidine $2^{\prime}$-monophosphate, cytidine $3^{\prime}$-monophosphate, thymidine $5^{\prime}$-monophosphate, and uridine $5^{\prime}$-monophosphate. Genome annotation provided a conflicting view as determined by the genes identified (Table S9). Twenty-nine phosphorus metabolism genes were broadly shared between C. sakazakii SP291 and C. sakazakii ATCC BAA-894, including eight high affinity phosphate transporters and control of pho-related regulon genes, 18 phosphate metabolism genes, and three polyphosphate genes. Cronobacter species cultured from a PIF production site were compared for their ability to grow in different food matrices (Cooney, 2012). Some demonstrated a slower growth rate compared to others, a feature that might contribute to their enhanced survival in this environment.

No differences in the metabolism of sulfur containing compounds were observed following a comparison of these strains after PM analysis (Figure 2A and Table S6). Forty-nine sulfur metabolism genes were shared by C. sakazakii ATCC BAA-894 and C. sakazakii SP291 (Table S10). These consisted of 17 inorganic sulfur assimilation genes, eight alkanesulfonate assimilation genes, five alkanesulfonates utilization genes, six L-cystine uptake and metabolism genes, four taurine utilization genes, three galactosylceramide and sulfatide metabolism genes, and six thioredoxin-disulfide reductase genes. 
Iron is an essential nutrient for bacterial growth and the process of iron acquisition is generally thought to be a prerequisite for a pathogen to establish an infection when entering a host, a feature previously reported in Cronobacter species (Crosa and Walsh, 2002; Franco et al., 2011; Grim et al., 2012). Highaffinity iron binding molecules, such as siderophores, and specific iron transport systems function to sequester iron from the environment when bacteria are subjected to iron-limiting growth conditions (Grim et al., 2012). Interestingly, analysis of the PM data showed no major differences between C. sakazakii SP291 and C. sakazakii ATCC BAA-894, in terms of their metabolism of iron or other nutrient supplements. Several transport systems were annotated in C. sakazakii SP291, and which are shared with C. sakazakii ATCC BAA-894 (Kucerova et al., 2010; Joseph et al., 2012), including a ferric hydroxamate ABC transporter denoted as FhuCDBA, 16 ferric enterobactin transporter proteins (including EntA, EntE, EntD, EntB, Fes, EntS, EntF, YbdZ, FepC, FepD, FepG, FepE, FepB, EntC, FepA2, and EntH), a ferrous iron transporter $\mathrm{EfeUOB}$, along with a hemin transporter system, including a ferric reductase protein FhuF and a periplasmic binding protein TonB. A gene summary of iron acquisition and metabolism markers in C. sakazakii SP291 chromosome is shown in Table S11.

Additionally, iron acquisition and metabolism genes were also identified on pSP291-1 (Table S5), which were indistinguishable from that previously reported to be present on pESA3 of $C$. sakazakii ATCC BAA-894 (Kucerova et al., 2010; Joseph et al., 2012) and pCTU1 of C. turicensis z3032 (Franco et al., 2011; Grim et al., 2012). Target genes from previous reports, such as

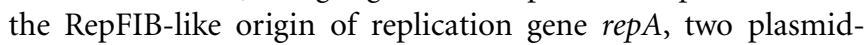
borne iron acquisition systems (eitCBAD and iucABCD/iutA), as well as the Cronobacter plasminogen activator cpa gene were all present in pSP291-1, with no evidence of the 17-kb type VI secretion system (T6SS) locus identified previously in pESA3 along with a 27-kb region encoding a filamentous hemagglutinin gene $(f h a B)$, its specifc transporter gene ( $f h a C)$, and associated putative adhesins (FHA locus) identified in pCTU1 (Kucerova et al., 2010; Franco et al., 2011; Grim et al., 2012, 2013; Joseph et al., 2012). These features support the hypothesis that these plasmids have evolved from a single archetypal backbone that included an iron acquisition system. Our sequence analysis and those of other groups (Joseph et al., 2012; Grim et al., 2013) did not find evidence of plasmid mobilization genes associated with the several plasmid group 1 genomes.

\section{Osmolyte tolerance and survival in different pH environments}

When present in different environments, bacteria must develop strategies that promote their survival. Genetic adaptation is derived from modifications of gene expression, via mutations, the acquisition of new and beneficial gene traits, or when these new traits are brought under control of a regulator that was already present in the core genome of the organism's ancestor (Maurelli, 2007). The outcome is that the organism is now better equipped to survive within the new ecological niche. It is generally thought that genes that are no longer compatible with the new lifestyle are selectively inactivated either by point mutation, insertion, or deletion and the contribution of gene loss to an organism's evolution is only now beginning to be appreciated (Maurelli, 2007). Based on our understanding of Cronobacter species epidemiology, these organisms are considered as environmental bacteria. Therefore their ability to survive adverse conditions would be critical. Phenotypes associated with growth in a range of osmolytes and in different $\mathrm{pH}$ growth environments were measured by $\mathrm{PM}$ analysis (Figure 2C and Table S6) as an indirect reflection of challenging environmental niches. In response to the presence of osmolytes, C. sakazakii SP291 could tolerate $100 \mathrm{mM}$ sodium nitrate compared with C. sakazakii ATCC BAA-894. In contrast, the former grew slower in solutions containing $5 \% \mathrm{NaCl}, 4 \%$ potassium chloride, $4 \%$ urea, $4-11 \%$ sodium lactate, $200 \mathrm{mM}$ sodium phosphate at $\mathrm{pH} 7$ and $20 \mathrm{mM}$ sodium benzoate at $\mathrm{pH}$ 5.2. These observations are consistent with what has been suggested previously, in that when a selected adaptation event occurs, and the bacterium enters a new environment such as the human host, phenotypes change (Tall, unpublished observations). Comparing the ability of the environmental isolate C. sakazakii SP291 to survive over a range of different $\mathrm{pH}$ growth conditions with that of the PIF isolate C. sakazakii ATCC BAA-894, the former grew faster in a growth condition of $\mathrm{pH} 9.5$ with phenylethylamine, whilst its growth was slower in $\mathrm{pH} 4.5$ with L-proline. This example demonstrates the gain of one phenotype consistent with the inability to survive in the human host (ability to survive in high $\mathrm{pH}$ growth conditions) compared to the loss of a sufficient acid resistance response. In this case, the pathoadaptative event that resulted in an increased persistence in the environment comes at the expense of decreased commensal fitness of the microbe (a patent acid response) to survive the acidity of the stomach. However, a greater number of genomes and strains should be evaluated to rule out strain to strain variation.

Annotation of the genome suggested that C. sakazakii SP291 contained a repertoire of genes that could function to aid survival under stressed conditions, such as osmolyte tolerance and different $\mathrm{pH}$ environments (Table 4). One hundred and fifty-two annotated genes were identified as being involved with various stress responses. Their presence in the genome may provide early insights into how C. sakazakii SP291 adapts to and survives under different stressful growth conditions.

In recent studies involving Salmonella species, a picture of the transcriptome in low-moisture growth conditions has begun to emerge (Frossard et al., 2012; Finn et al., 2013). Allied to this, 25 genes involved in osmotic stress, and covering $16.4 \%$ of the stress response genes were identified in C. sakazakii SP291. Interestingly, the osmoprotectant ABC transporter denoted as YehZYXW in the Cronobacter genome, together with the L-proline glycine betaine MFS transporter ProP, and the ABC transporter ProU systems (composed of ProV, ProW, ProX) designed in Escherichia coli (Checroun and Gutierrez, 2004) and Salmonella Typhimurium (Cairney et al., 1985) were identified in the C. sakazakii SP291 genome. Moreover, an osmoregulator transporter including genes opuCA, ориCB, ориCC, and a fourth gene, which was also an $\mathrm{ABC}$ transporter denoted as $o p u C D$ here, was $77 \%$ similar to that of the osmU operon (osmVWXY) in Salmonella (Frossard et al., 2012) at the gene level. Other osmotically functioning genes identified included the betaine/carnitine/choline transporter (BCCT) family, which acts to transport betaine and choline. This operon 
Table 4 | A selection of the stress response-encoding genes, the defined sub-system, together with the gene name, length of the ORF and correspondoing function, identified in C. sakazakii SP291.

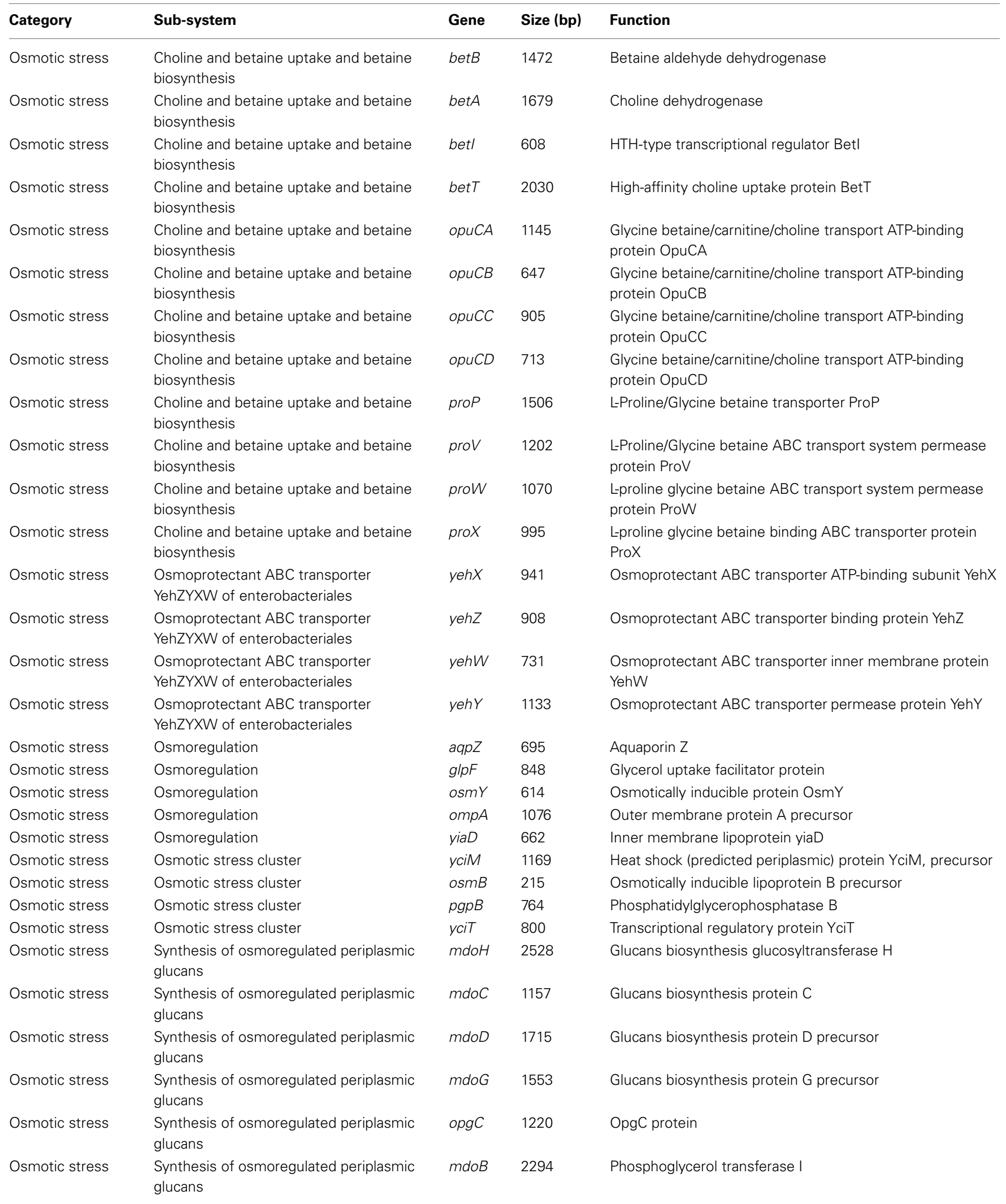


Table 4 | Continued

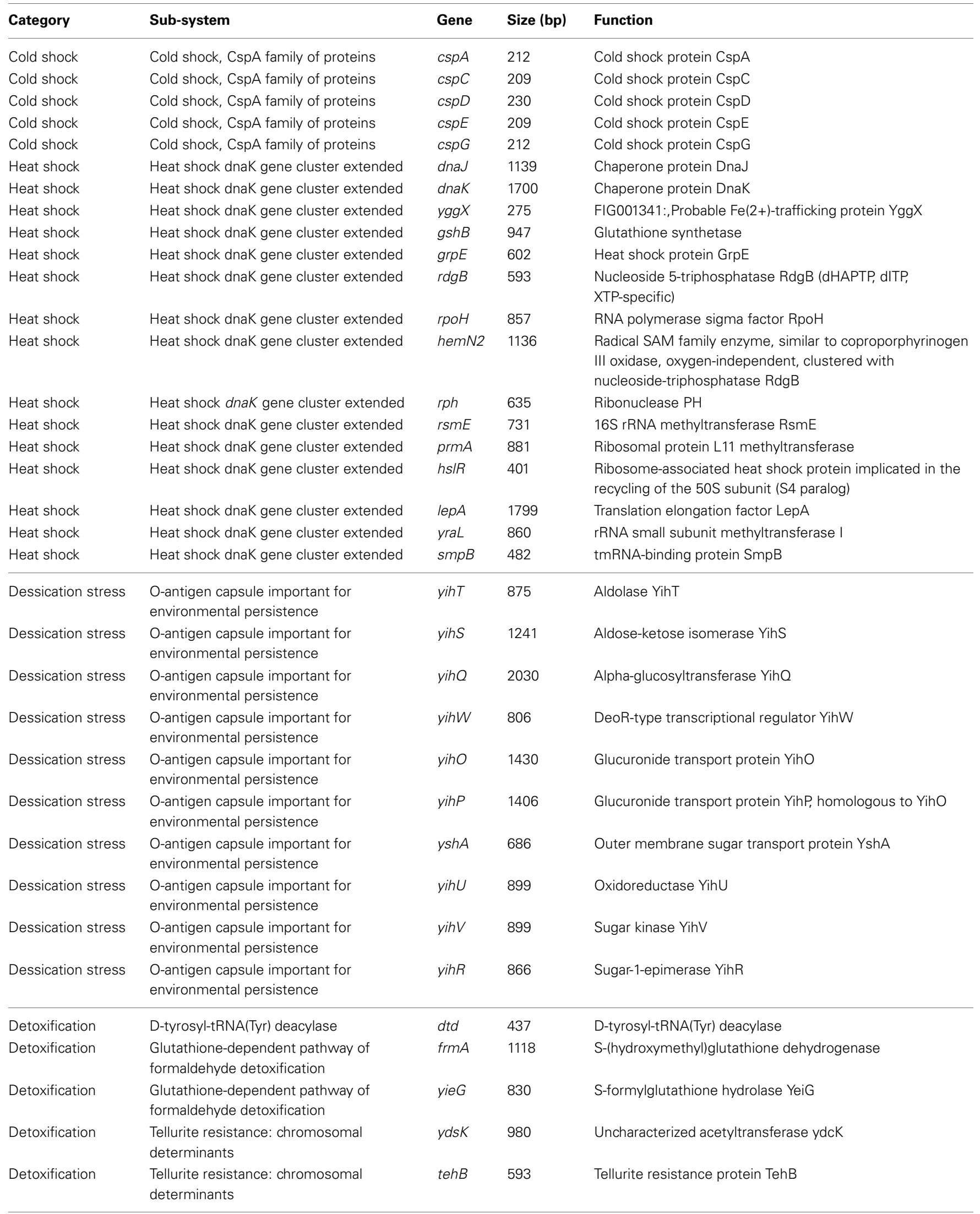


Table 4 | Continued

\begin{tabular}{|c|c|c|c|c|}
\hline Category & Sub-system & Gene & Size (bp) & Function \\
\hline Detoxification & $\begin{array}{l}\text { Tellurite resistance: chromosomal } \\
\text { determinants }\end{array}$ & $y d c L$ & 668 & Uncharacterized lipoprotein ydcL \\
\hline Detoxification & Uptake of selenate and selenite & $\operatorname{ded} A$ & 659 & DedA protein \\
\hline Detoxification & Uptake of selenate and selenite & cysA & 1094 & Sulfate and thiosulfate import ATP-binding protein CysA \\
\hline Detoxification & Uptake of selenate and selenite & $\operatorname{tsg} A$ & 1187 & TsgA protein homolog \\
\hline Oxidative stress & Glutaredoxins & yebA & 1331 & Uncharacterized metalloprotease yebA \\
\hline Oxidative stress & Glutaredoxins & yibP & 1259 & Uncharacterized protein yibP \\
\hline Oxidative stress & Glutaredoxins & hmp & 1190 & $\begin{array}{l}\text { Flavohemoprotein (Hemoglobin-like protein) } \\
\text { (Flavohemoglobin) (Nitric oxide dioxygenase) }\end{array}$ \\
\hline Oxidative stress & Glutaredoxins & $\operatorname{grx} B$ & 647 & Glutaredoxin 2 \\
\hline Oxidative stress & Glutaredoxins & $\operatorname{grxC}$ & 251 & Glutaredoxin 3 (Grx3) \\
\hline Oxidative stress & Glutaredoxins & $n r d H$ & 245 & $\begin{array}{l}\text { Glutaredoxin-like protein } \mathrm{NrdH} \text {, required for reduction of } \\
\text { Ribonucleotide reductase class } \mathrm{lb}\end{array}$ \\
\hline Oxidative stress & Glutaredoxins & $g r / A$ & 347 & Probable monothiol glutaredoxin GrlA \\
\hline Oxidative stress & $\begin{array}{l}\text { Glutathione: biosynthesis and } \\
\text { gamma-glutamyl cycle }\end{array}$ & $g g t$ & 1766 & Gamma-glutamyltranspeptidase \\
\hline Oxidative stress & $\begin{array}{l}\text { Glutathione: biosynthesis and } \\
\text { gamma-glutamyl cycle }\end{array}$ & $g \operatorname{sh} A$ & 1556 & Glutamate-cysteine ligase \\
\hline Oxidative stress & $\begin{array}{l}\text { Glutathione: biosynthesis and } \\
\text { gamma-glutamyl cycle }\end{array}$ & $g \operatorname{sh} B$ & 947 & Glutathione synthetase \\
\hline Oxidative stress & Glutathione: non-redox reactions & $r n h A$ & 716 & FIG005121: SAM-dependent methyltransferase \\
\hline Oxidative stress & Glutathione: non-redox reactions & gst1 & 668 & Glutathione S-transferase \\
\hline Oxidative stress & Glutathione: non-redox reactions & $\operatorname{yghU}$ & 866 & Uncharacterized Glutathione S-transferase like protein yghU \\
\hline Oxidative stress & Glutathione: non-redox reactions & gst & 608 & Glutathione S-transferase \\
\hline Oxidative stress & Glutathione: non-redox reactions & yqjG & 986 & Uncharacterized protein yqjG \\
\hline Oxidative stress & Glutathione: non-redox reactions & $g l o B$ & 755 & Hydroxyacylglutathione hydrolase \\
\hline Oxidative stress & Glutathione: non-redox reactions & gloA & 407 & Lactoylglutathione lyase \\
\hline Oxidative stress & Glutathione: non-redox reactions & $y f c F$ & 644 & Probable glutathione S-transferase, YfcF homolog \\
\hline Oxidative stress & Glutathione: non-redox reactions & $y f c G$ & 626 & Probable glutathione S-transferase, YfcG homolog \\
\hline Oxidative stress & Glutathione: non-redox reactions & yibF & 608 & Uncharacterized GST-like protein yibF \\
\hline Oxidative stress & Glutathione: non-redox reactions & ylis & 626 & Uncharacterized glutathione S-transferase-like protein \\
\hline Oxidative stress & Glutathione: redox cycle & $\operatorname{grx} B$ & 635 & Glutaredoxin 2 \\
\hline Oxidative stress & Glutathione: redox cycle & $\operatorname{grx} C$ & 251 & Glutaredoxin 3 (Grx3) \\
\hline Oxidative stress & Glutathione: redox cycle & $n r d H$ & 245 & $\begin{array}{l}\text { Glutaredoxin-like protein } \mathrm{NrdH} \text {, required for reduction of } \\
\text { Ribonucleotide reductase class } \mathrm{lb}\end{array}$ \\
\hline Oxidative stress & Glutathione: redox cycle & btuE & 551 & Glutathione peroxidase \\
\hline Oxidative stress & Glutathione: redox cycle & lpd & 1427 & Glutathione reductase \\
\hline Oxidative stress & Glutathione: redox cycle & gor & 1352 & Glutathione reductase \\
\hline Oxidative stress & Glutathionylspermidine and Trypanothione & yjfC & 1187 & Uncharacterized protein yjfC \\
\hline Oxidative stress & Glutathionylspermidine and Trypanothione & ygiC & 1160 & Uncharacterized protein ygiC \\
\hline Oxidative stress & NADPH:quinone oxidoreductase 2 & $y t f G$ & 854 & Uncharacterized oxidoreductase ytfG \\
\hline Oxidative stress & NADPH:quinone oxidoreductase 2 & qorR & 380 & Redox-sensing transcriptional regulator QorR \\
\hline Oxidative stress & Oxidative stress & katG & 2180 & Catalase/peroxidase HPI \\
\hline Oxidative stress & Oxidative stress & katE & 2255 & Hydroperoxidase II \\
\hline Oxidative stress & Oxidative stress & fur & 452 & Ferric uptake regulation protein FUR \\
\hline Oxidative stress & Oxidative stress & $d p s$ & 503 & DNA protection during starvation protein \\
\hline Oxidative stress & Oxidative stress & fnr & 752 & Fumarate and nitrate reduction regulatory protein \\
\hline Oxidative stress & Oxidative stress & oxyR & 917 & DNA-binding transcriptional regulator OxyR \\
\hline Oxidative stress & Oxidative stress & $d p s$ & 503 & DNA protection during starvation protein \\
\hline Oxidative stress & Oxidative stress & $\operatorname{sod} A$ & 626 & Manganese superoxide dismutase \\
\hline Oxidative stress & Oxidative stress & $n s r R$ & 353 & Nitrite-sensitive transcriptional repressor NsrR \\
\hline Oxidative stress & Oxidative stress & $d p S$ & 503 & Non-specific DNA-binding protein Dps \\
\hline Oxidative stress & Oxidative stress & osmC & 428 & Organic hydroperoxide resistance \\
\hline
\end{tabular}


Table 4 | Continued

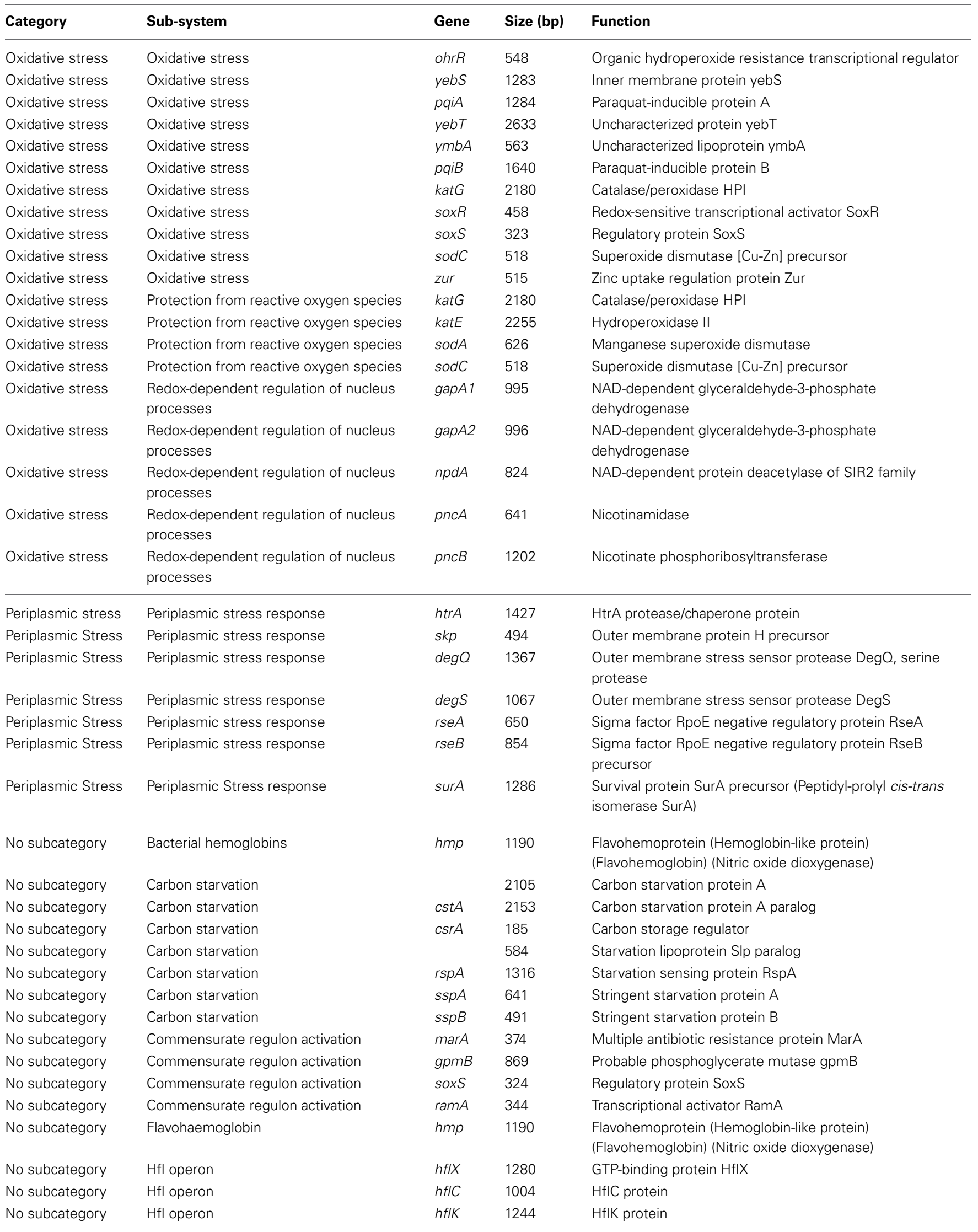


Table 4 | Continued

\begin{tabular}{|c|c|c|c|c|}
\hline Category & Sub-system & Gene & Size (bp) & Function \\
\hline No subcategory & Hfl operon & yjeT & 197 & Putative inner membrane protein YjeT (clustered with $\mathrm{HfIC}$ ) \\
\hline No subcategory & Hfl operon & $h f q$ & 308 & RNA-binding protein $\mathrm{Hfq}$ \\
\hline No subcategory & Phage shock protein (psp) operon & $\operatorname{pspA}$ & 671 & Phage shock protein A \\
\hline No subcategory & Phage shock protein (psp) operon & $p s p B$ & 224 & Phage shock protein B \\
\hline No subcategory & Phage shock protein (psp) operon & $p s p C$ & 356 & Phage shock protein $\mathrm{C}$ \\
\hline No subcategory & Phage shock protein (psp) operon & $p s p D$ & 242 & Phage shock protein D \\
\hline No subcategory & Phage shock protein (psp) operon & $p s p F$ & 1001 & Psp operon transcriptional activator \\
\hline No subcategory & Sugar-phosphate stress regulation & $\operatorname{sgrR}$ & 1664 & $\begin{array}{l}\text { SgrR, sugar-phosphate stress, transcriptional activator of } \\
\text { SgrS small RNA }\end{array}$ \\
\hline No subcategory & Universal stress protein family & uspA & 437 & Universal stress protein A \\
\hline No subcategory & Universal stress protein family & $u s p B$ & 335 & Universal stress protein B \\
\hline No subcategory & Universal stress protein family & uspC & 422 & Universal stress protein $\mathrm{C}$ \\
\hline No subcategory & Universal stress protein family & uspE & 956 & Universal stress protein E \\
\hline No subcategory & Universal stress protein family & uspG & 428 & Universal stress protein G \\
\hline
\end{tabular}

consists of a high-affinity choline uptake gene bet T, a helixturn-helix (HTH)-type transcriptional regulator betI, which was previously identified in E. coli (Lamark et al., 1991), a betaine aldehyde dehydrogenase $b e t B$ gene and a choline dehydrogenase gene betA. An in silico assessment of those loci involved in osomotolerance comparing Cronobacter sakazakii ATCC BAA-894 and E. coli K12 MG1655 identified these latter features also (Feeney and Sleator, 2011). Interestingly, several other genes linked to osmotic stress conditions were identified in the genome of $C$. sakazakii SP291, which included five osmoregulation genes ( $a q p Z, g l p F$, osm $Y, \operatorname{omp} A$, and $y i a D$ ), four osmotic stress cluster genes (yciM, $o s m B, p g p B$, and $y c i T)$ and six osmoregulated periplasmic glucan genes $(m d o H, m d o C, m d o D, m d o G, o p g C$ and $m d o B)$. None of these genes were identified previously by Feeney and Sleator (2011). Finally, ompA which encodes an outer membrane porin, was identified in C. sakazakii SP291 and is a recognized virulence marker (Kim et al., 2010).

Experiments to investigate the nature of the C. sakazakii responses to cold- and heat-shock conditions have been reported (Shaker et al., 2008; Carranza et al., 2010; Chang et al., 2010; AlNabulsia et al., 2011; Gajdosova et al., 2011). Following exposure to extreme temperatures of cold-shock at $-20^{\circ} \mathrm{C}$, or heat-shock at $47^{\circ} \mathrm{C}$, survival of Cronobacter sakazakii was significantly enhanced (Chang et al., 2010). Carranza et al. (2010) reported that when exposed to higher temperatures, several potential virulence factors were up-regulated. The fact that the pathogenic potential of Cronobacter species may be related to its ability to survive at higher temperatures, warrents further investigation. From the genome sequence of $C$. sakazakii SP291, the cspA family of coldshock genes (including $\operatorname{csp} A, \operatorname{csp} C, \operatorname{csp} D, \operatorname{csp} E$ and $\operatorname{csp} G$ ) along with 11 other genes annotated as heat-shock genes, part of the $d n a K$ gene cluster, including $d n a J$, dnaK, $y g g X, g s h B, g r p E, r d g B$, $r p o H$, hemN2, rph, rsmE, prmA, hslR, yraL, and smpB genes were conserved.

Using a top-down proteomics approach, Williams et al. (2005) identified a candidate protein in C. sakazakii, known to be associated with thermotolerance in Methylobacillus flagelatum, and which was denoted as KT. In a recent study, the genomic region

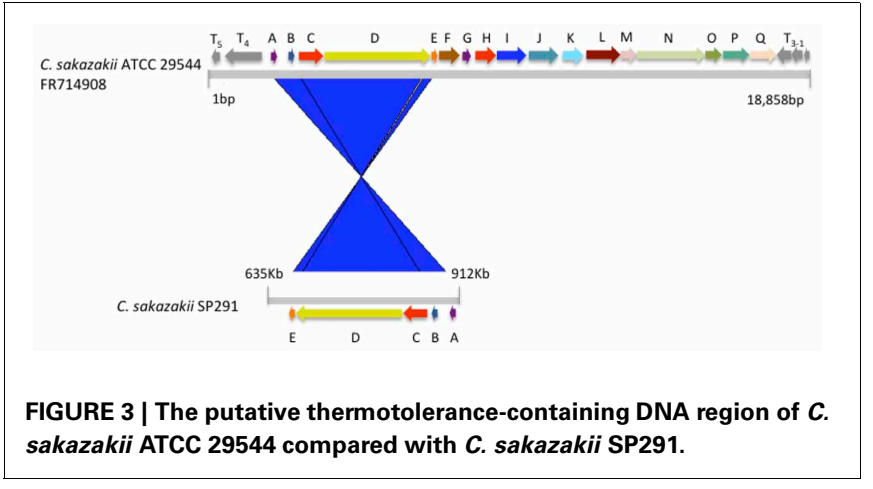

containing this presumptive marker of thermotolerance was compared to similar regions in other bacteria (Gajdosova et al., 2011). An in silico analysis showed that this thermotolerace KT-region was present in 4 of 14 isolates consisting of seven Cronobacter species studied by Joseph et al. (2012). Cronobacter sakazakii SP291 can survive desiccation for long periods of time at an average temperature of $56.7^{\circ} \mathrm{C}$, similar to that recorded when spray drying is in operation during PIF production (Cooney, 2012). Interestingly, C. sakazakii SP291 was negative for the KT marker, as determined by PCR (data not shown). Apart from the locus between orfA-orfE, when the corresponding region of the SP291 genome was compared to that of C. sakazakii ATCC 29,544, this region was devoid of the KT-encoding homolog (Figure 3). In light of the thermo-adapted phenotype possessed by C. sakazakii SP291, this finding suggests that there may be other thermotolerance survival mechanisms expressed by C. sakazakii SP291.

As mentioned above, Cronobacter species have the capacity to survive in desiccated environments for long periods, a phenotype that is linked to their epidemiology and routes of infection. As an example of genes linked to this phenotype, the $y$ ih-encoding operons, consisted of 10 annotated genes present in the genome of $C$. sakazakii SP291. Desiccation-related proteins YihU, YihT, YihR, YihS, YihQ and YihV have conserved domains which function in carbohydrate transport and metabolism. YihO is a glucuronide 
Table 5 | Comparison of the differential phenotypes expressed by $C$. sakazakii SP291 and C. sakazakii ATCC BAA-894 related to antimicrobial and toxic compounds as determined by phenotype microarray.

\begin{tabular}{|c|c|c|}
\hline Test compound & Difference $^{a}$ & Mode of action \\
\hline \multicolumn{3}{|c|}{ PHENOTYPES GAINED BY C. sakazakii SP291 RELATIVE TO } \\
\hline \multicolumn{3}{|c|}{ C. sakazakii ATCC BAA-894- } \\
\hline Amoxicillin & 20,446 & Wall, lactam \\
\hline Neomycin & 47,681 & $\begin{array}{l}\text { Protein synthesis, } 30 \text { S ribosomal } \\
\text { subunit, aminoglycoside }\end{array}$ \\
\hline Sisomicin & 40,297 & $\begin{array}{l}\text { Protein synthesis, } 30 \text { S ribosomal } \\
\text { subunit, aminoglycoside }\end{array}$ \\
\hline Tobramycin & 33,297 & $\begin{array}{l}\text { Protein synthesis, } 30 \text { S ribosomal } \\
\text { subunit, aminoglycoside }\end{array}$ \\
\hline Sodium arsenate & 22,155 & Toxic anion, PO4 analog \\
\hline Sodium metaborate & 65,231 & Toxic anion \\
\hline EDTA & 89,134 & Chelator, hydrophilic \\
\hline $\begin{array}{l}\text { 5,7-Dichloro-8- } \\
\text { hydroxyquinoline }\end{array}$ & 21,638 & Chelator, lipophilic \\
\hline $\begin{array}{l}\text { 5-Nitro-2-furaldehyde } \\
\text { semicarbazone }\end{array}$ & 40,348 & $\begin{array}{l}\text { DNA damage, multiple sites, } \\
\text { nitrofuran analog }\end{array}$ \\
\hline Protamine sulfate & 27,720 & Membrane, non-specific binding \\
\hline Streptomycin & 40,297 & $\begin{array}{l}\text { Protein synthesis, } 30 \text { S ribosomal } \\
\text { subunit, aminoglycoside }\end{array}$ \\
\hline Potassium tellurite & 27,025 & Toxic anion \\
\hline Sodium tungstate & 50,849 & Toxic anion, molybdate analog \\
\hline Poly-L-lysine & 43,324 & Membrane, detergent, cationic \\
\hline Sodium m-arsenite & 28,927 & Toxic anion \\
\hline Sodium periodate & 47,820 & Toxic anion, oxidizing agent \\
\hline $\begin{array}{l}\text { Antimony (III) } \\
\text { chloride }\end{array}$ & 35,457 & Toxic cation \\
\hline $\begin{array}{l}\text { lodonitro tetrazolium } \\
\text { violet }\end{array}$ & 22,427 & Respiration \\
\hline $\begin{array}{l}\text { Hexamminecobalt } \\
\text { (III) Chloride }\end{array}$ & 30,202 & DNA synthesis \\
\hline Apramycin & 43,717 & $\begin{array}{l}\text { Protein synthesis, } 30 \text { S ribosomal } \\
\text { subunit, aminoglycoside }\end{array}$ \\
\hline Ornidazole & 22,594 & Protein glycosolation \\
\hline \multicolumn{3}{|c|}{ PHENOTYPES LOST BY C. sakazakii SP291 RELATIVE TO } \\
\hline \multicolumn{3}{|c|}{ C. sakazakii ATCC BAA-894- } \\
\hline Cloxacillin & $-20,939$ & Wall, lactam \\
\hline Colistin & $-35,638$ & Membrane, transport \\
\hline $\begin{array}{l}\text { Guanidine } \\
\text { hydrochloride }\end{array}$ & $-47,347$ & Membrane, chaotropic agent \\
\hline Cefmetazole & $-21,713$ & $\begin{array}{l}\text { Wall, cephalosporin second } \\
\text { generation }\end{array}$ \\
\hline Phleomycin & $-45,183$ & $\begin{array}{l}\text { DNA damage, oxidative, ionizing } \\
\text { ratiation }\end{array}$ \\
\hline Methyl viologen & $-81,565$ & Oxidizing agent \\
\hline Sodium azide & $-22,375$ & Respiration, uncoupler \\
\hline Dichlofluanid & $-42,205$ & Fungicide, phenylsulphamide \\
\hline Cinoxacin & $-18,744$ & $\begin{array}{l}\text { DNA unwinding, gyrase (GN), } \\
\text { topoisomerase (GP), quinolone }\end{array}$ \\
\hline Rifamycin SV & $-22,130$ & RNA polymerase \\
\hline Glycine hydroxamate & $-64,946$ & tRNA synthetase \\
\hline $\begin{array}{l}\mathrm{D}, \mathrm{L}-\text { Methionine } \\
\text { hydroxamate }\end{array}$ & $-38,317$ & tRNA synthetase \\
\hline
\end{tabular}

(Continued)
Table 5 | Continued

\begin{tabular}{lll}
\hline Test compound & Difference $^{\text {a }}$ & Mode of action \\
\hline Sodium bromate & $-27,123$ & Toxic anion \\
Guanazole & $-33,164$ & Ribonucleotide DP reductase \\
Ciprofloxacin & $-22,172$ & $\begin{array}{l}\text { DNA unwinding, gyrase (GN), } \\
\text { topoisomerase (GP), } \\
\end{array}$ \\
& $-18,317$ & $\begin{array}{l}\text { fluoroquinolone } \\
\text { Tolylfluanid }\end{array}$ \\
\hline
\end{tabular}

${ }^{a}$ Denotes the following: a positive number indicates faster growth in C. sakazakii SP291 compared to C. sakazakii ATCC BAA-894; a negative number indicates faster growth in C. sakazakii ATCC BAA-894 compared to C. sakazakii SP291.

transport protein whilst YihP is homologous to it. YshA is an outer membrane sugar transport protein and YihW is a deoRtype transcriptional regulator, reported to negatively regulate the expression of yihU-oyshA in Salmonella (Gibson et al., 2006). This operon was reported to be up-regulated following desscication stress in Salmonella. Interstingly, the yih operon are conserved in 17 annotated Cronobacter genomes (strain information of the genomes are listed in Table $\mathbf{1}$ ) and noted previously (Grim et al., 2013).

The ability of a bacterium to eliminate toxic compounds from the cell is an important survival mechanism. Nine genes involved in detoxification were identified in the C. sakazakii SP291 genome. These included a tellurite resistance-encoding gene tehB, which matches a $593 \mathrm{bp}$ hypothetical protein in $C$. sakazakii ATCC BAA-894. However, a tellurite resistance region (terACDYZ) was reported only in C. sakazakii ATCC BAA-894 (Table 4), and with the exception of the terC-encoding marker in C. turicensis z3032, was not identified in any of the other Cronobacter species genomes sequenced (Kucerova et al., 2010; Joseph et al., 2012; Grim et al., 2013). Genes involved in the detoxification of organic pollutants, including a D-tyrosyl-tRNA (Tyr) deacylase-encoding $d t d$, two glutathione-dependent pathway formaldehyde detoxification genes ( $f r m A$ and $y i e G)$, three genes involved in the uptake of selenate and selenite $(\operatorname{ded} A, c y s A$, and its homolog $\operatorname{tsg} A$ ), and two uncharacterized genes ( $y d s K$ and $y d c L$ ), were also identified in C. sakazakii SP291. This feature supports an earlier report describing the ability of Cronobacter species to detoxify and survive in tannery wastewater effluents (Chandra et al., 2011).

Oxidative stress is an example of an important bacterial stress response, with 62 annotated genes covering $40.8 \%$ genome linked to this sub-system. These genes included the zinc uptake regulation zur, which was reported as involved in the oxidative stress response of Streptomyces coelicolor (Shin et al., 2007). Other stress-related genes included seven periplasmic stress related genes, a bacterial hemoglobin gene, seven genes involved in carbon starvation, four commensurate regulon activation genes, a flavohaemoglobin gene, five $h f l$ operon genes, five phage shock protein ( $p s p)$ operon genes, a sugar-phosphate stress regulation gene, and five universal stress protein family genes.

\section{Resistance to antibiotics and toxic compounds}

C. sakazakii was originally reported to be susceptible to a panel of 69 antimicrobial agents (Stock and Wiedemann, 2002). Subsequently, a tetracycline-resistant C. sakazakii cultured from 
Table 6 | Genes related to resistance to antibiotics and toxic compounds annotated in C. sakazakii SP291 and C. sakazakii ATCC BAA-894.

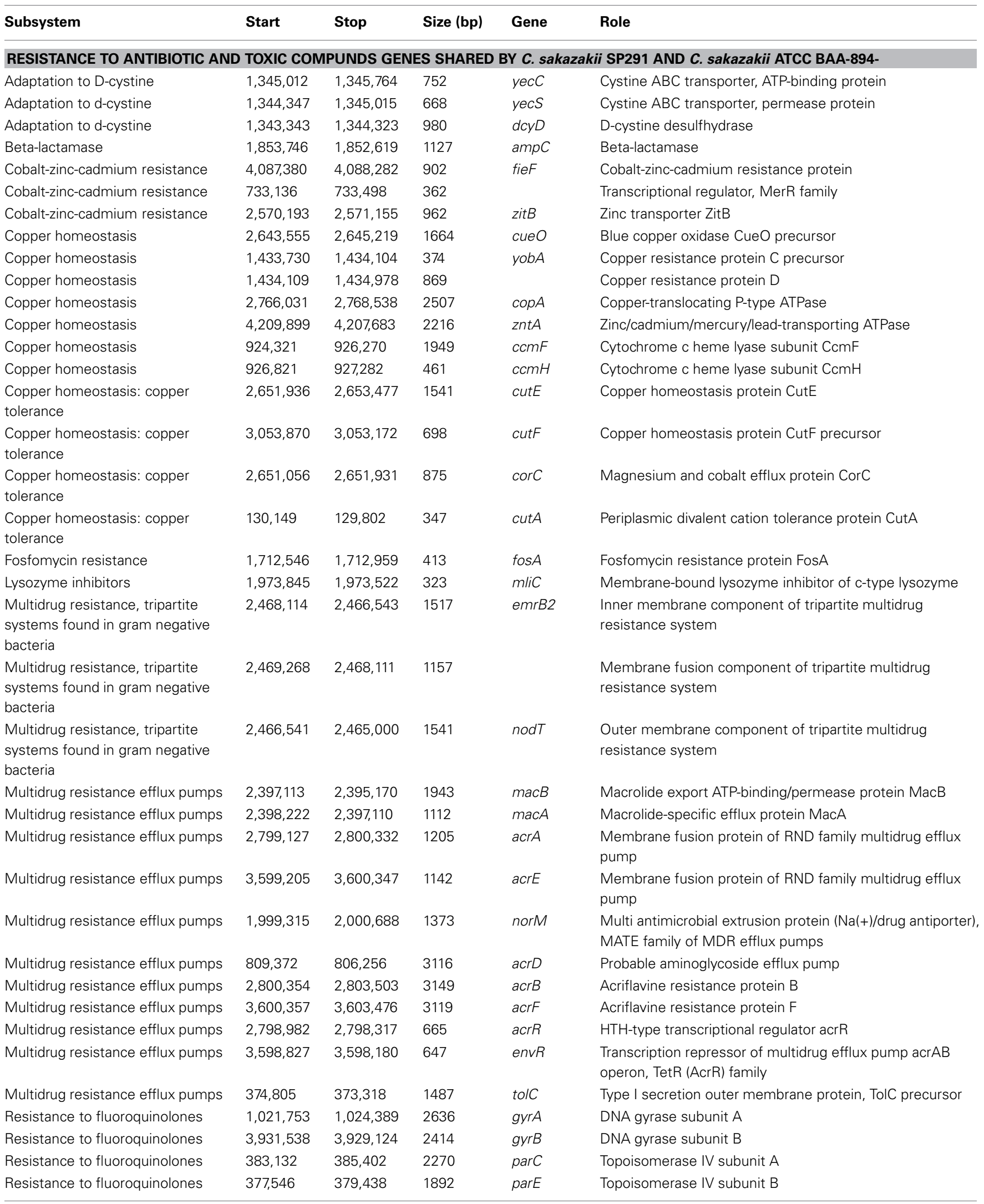


Table 6 | Continued

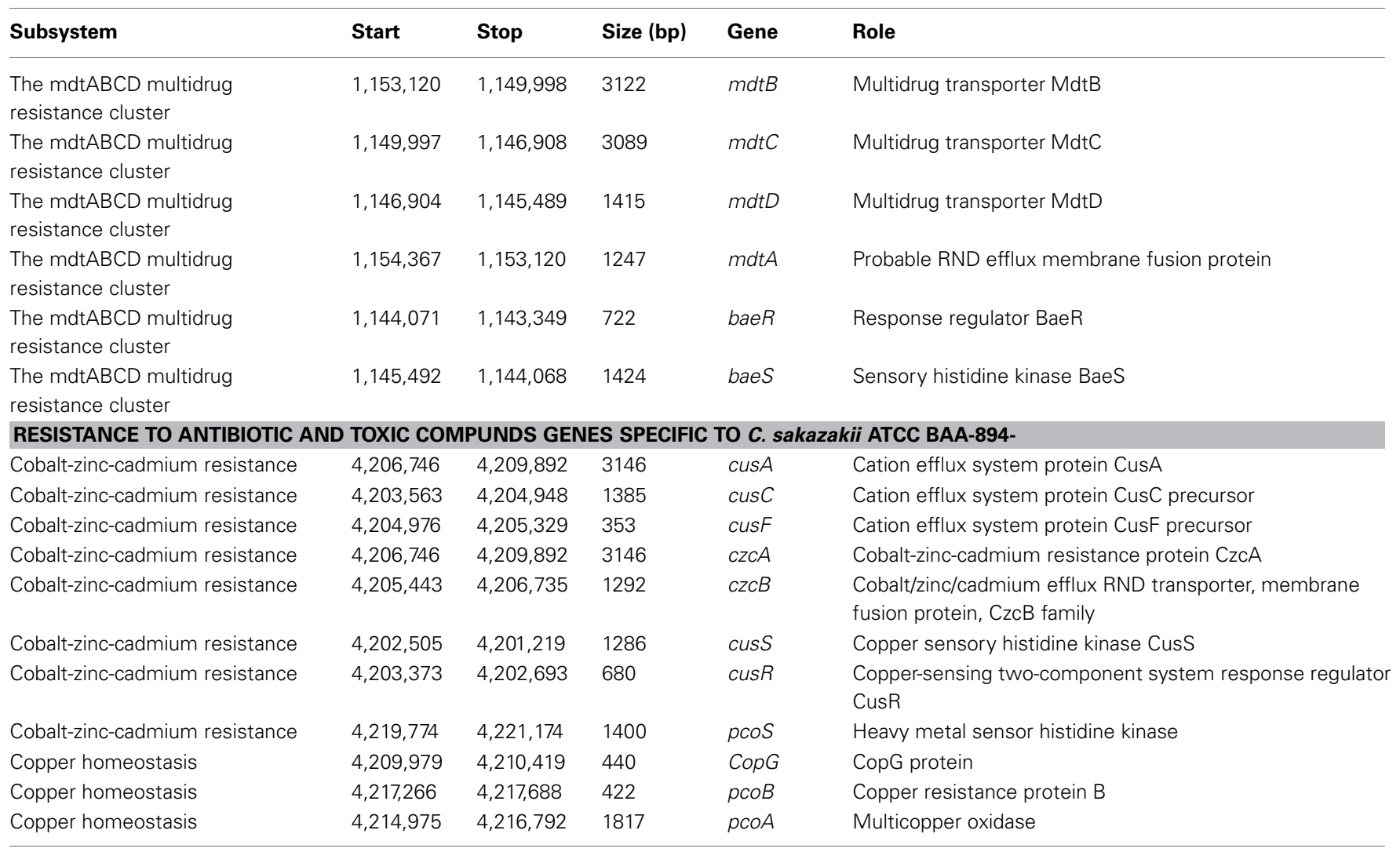

a Chilean freshwater salmon farm (Miranda et al., 2003) was isolated, followed by a report of a trimethoprim and neomycin resistance isolate cultured from fresh domiati cheese (El-Sharoud et al., 2009). More recently, isolates resistant to cephalothin were recovered from dried food (Chon et al., 2012). The emergence of strains that have become resistant to antimicrobial compounds is of great concern to public health (Dumen, 2010; Yan et al., 2012).

Figure 2D shows a heat map comparing C. sakazakii SP291 and C. sakazakii ATCC BAA-894 and Table 5 provides a summary of the significant changes in PM redox measurements, after bacterial growth in microtitre wells containing a number of antimicrobial compounds as part of the phenotypic microarray. Compared to C. sakazakii ATCC BAA-894, C. sakazakii SP291 exhibited more activity in the presence of 5,7-dichloro8-hydroxyquinoline, 5-nitro-2-furaldehyde semicarbazone, hexamminecobalt (III) chloride, poly-L-lysine, protamine sulfate, ornidazole, tobramycin, streptomycin, apramycin, iodonitro tetrazolium violet, amoxicilin, neomycin, and sisomicin; while exhibiting a reduced activity in the presence of phleomycin, ciprofloxacin, cinoxacin, dichlofluanid, tolylfluanid, guanidine hydrochloride, colistin, methyl viologen, sodium azide, guanazole, rifamycin SV, glycine hydroxamate, D,L-methionine hydroxamate, cefmetazole, and cloxacillin.

Careful analysis of the PM data showed an interesting phenotype, related to bioactive and toxic anions. C. sakazakii SP291 survived significantly better in sodium metaborate, potassium tellurite, sodium m-arsenite, sodium tungstate, sodium periodate, sodium arsenate, and antimony (III) chloride compared with $C$. sakazakii ATCC BAA-894. In contrast the latter bacterium, exhibited a distinct phenotype in sodium bromate. These observations suggested that C. sakazakii SP291 elaborates a greater ability to counter the effects of a broader range of heavy metals, a characteristic that could be facilitate adaptation in powered infant formula manufacturing environments where metallic compositions such as quaternary containing disinfectants are used for decontamination. This resistance phenotype may be globally regulated as well. Together, this information may explain how this organism adapted to the manufacturing environment.

Based in part on these phenotypes, a total of 44 genes were shared between $C$. sakazakii ATCC BAA-894 and C. sakazakii SP291. These consisted of adaptation to D-cysteine related genes (include yecC, yecS, and $d c y D$ ), a $\beta$-lactamaseencoding ampC gene, three cobalt-zinc-cadmium resistance genes (including $f e i F, z i t B$ and a MerR family transcriptional regulator), 11 copper homeostasis genes (include cueO, yobA, $\operatorname{cop} A$, $z n t A, c c m F, c c m H, c u t E, c u t F, c o r C, c u t A$, and a copper resistance protein $\mathrm{D}$ gene), a fosfomycin resistance gene fos $A$, a lysozyme inhibitor $m l i C$, a tripartite multidrug resistance system found in Gram-negative bacteria, 11 multidrug resistance efflux pumps (including macB, macA, acrA, acrE, norM, acrD, $a c r B, a c r F$, acrR, envR, and tolC), four genes encoding resistance to fluoroquinolones (including $g y r A, \operatorname{gyr} B$, parC, and $\operatorname{parE}$ ), and a multidrug resistance cluster (consisting of $m d t B, m d t C$, $m d t D, m d t A, b a e R$, and baeS). All of these genes mapped to 
the bacterial chromosome. In addition three arsenic resistance genes were identified on pSP291-1 (Table S5). This latter feature confirmed the previous report on the copper/silver resistance determinants in Cronobacter species (Kucerova et al., 2010; Sivamaruthi et al., 2011; Joseph and Forsythe, 2012; Joseph et al., 2012; Grim et al., 2013). In contrast, eight cobalt-zinc-cadmium resistance genes (include $c u s A, c u s C, c u s F, c z c A, c z c B, c u s S, c u s R$, and $p c o S$ ) and three copper homeostasis genes (including $\operatorname{cop} G$, $p c o B$ and $p c o A$ ) were unique to $C$. sakazakii ATCC BAA-894, of which cusRCFBA/silRECBA and pcoABCDR were indicated as two copper and silver resistance regions. The previous region was shared among C. sakazakii, C. malonaticus, and C. turicensis; while the latter region was shared among C. sakazakii, C. malonaticus, C. turicensis and C. universalis (Joseph et al., 2012) (Table 6).

\section{CONCLUSIONS}

Stress responses and resistance to antibiotic and toxic compounds are interesting phenotypes identified in $C$. sakazakii SP291, when compared to C. sakazakii ATCC BAA-894, based on the comparative phenotypic microarray analysis in parallel with the annotation of its genome. Given this the fact that the PIF production environment is a stressful ecological niche, the osmoprotectant ABC transporters including YehZYXW, ProP, ProU, and OpuCABCD can be expected to play a role to support bacterial survival, as reported in other microorganisms previously (Cairney et al., 1985; Checroun and Gutierrez, 2004; Frossard et al., 2012; Finn et al., 2013). Notably, C. sakazakii SP291 possesses a greater ability to survive in a broader range of heavy metals, as quaternary containing disinfectants which include metallic compositions are often used for PIF manufacturing environment disinfection. In conclusion, genome analysis of C. sakazakii SP291 along with its metabolome highlighted a number of potential features, which might be considered as candidates for future studies to extend our understanding of the persistence and virulence mechanisms deployed by this bacterium in the production environment. These data provide an early insight into how a factory isolate may survive in a desiccation condition and adapt to the PIF production environment and associated food matrices.

\section{ACKNOWLEDGMENTS}

We thank Drs. Marta Martins and Orla Condell for their assistance with the PM data analysis and to Ms. Sarah Finn for critical reading of the manuscript.

\section{REFERENCES}

Al-Nabulsia, A. A., Osailia, T. M., Zain Elabedeena, N. A., Jaradatb, Z. W., Shakera, R. R., Kheirallahc, K. A., et al. (2011). Impact of environmental stress desiccation, acidity, alkalinity, heat or cold on antibiotic susceptibility of Cronobacter sakazakii. Int. J. Food Microbiol. 146, 137-143. doi: 10.1016/j.ijfoodmicro.2011.02.013

Arku, B., Fanning, S., and Jordan, K. (2011). Heat adaptation and survival of Cronobacter spp. (formerly Enterobacter sakazakii). Foodborne Pathog. Dis. 8, 975-981. doi: 10.1089/fpd.2010.0819
Aziz, R. K., Bartels, D., Best, A. A., DeJongh, M., Disz, T., Edwards, R. A., et al. (2008). The RAST Server: rapid annotations using subsystems technology. BMC Genomics 9:75. doi: 10.1186/1471-2164-9-75

Bar-Oz, B., Preminger, A., Peleg, O., Block, C., and Arad, I. (2001). Enterobacter sakazakii infection in the newborn. Acta Paediatr. 90, 356-358. doi: 10.1080/080352501300067857

Baumgartner, A., Grand, M., Liniger, M., and Iversen, C. (2009). Detection and frequency of Cronobacter spp. (Enterobacter sakazakii) in different categories of

\section{SUPPLEMENTARY MATERIAL}

The Supplementary Material for this article can be found online at: http://www.frontiersin.org/Food_Microbiology/10.3389/ fmicb.2013.00256/abstract

Table S1 | Genomic regions missing in $C$. sakazakii SP291 when compared to the other three completed genomes of $C$. sakazakii ATCC BAA-894 (as the reference sequence), C. sakazakii E15 and C. turicensis z3032.

Table S2 | Genomic regions present only in C. sakazakii SP291 (as the reference sequence) when compared to the other three completed genomes of $C$. sakazakii ATCC BAA-894, C. sakazakii ES15 and C. turicensis z3032.

Table S3 | Genome comparison of $C$. sakazakii SP291 with other available C. sakazakii genomes, which include $C$. sakazakii SP291, ATCC BAA-894, ES15, E899, 680, 696, 701, ES35, 2151, ES713, and E764.

Table S4 | Genome comparison of C. sakazakii SP291 with Cronobacter isolate of other six species, which consist of $C$. dublinensis LMG 23823, $C$. malonaticus LMG 23826, C. muytjensii ATCC 51329, C. turicensis z3032, C. universalis NCTC 9529, and C. condimenti 1330.

Table S5 | Annotated plasmid clusters of three complete genome, which include pSP291-1, pSP291-2, and pSP291-3 of $C$. sakazakii SP291, pESA2 and pESA3 of $C$. sakazakii ATCC BAA-894, as well as pCTU1, pCTU2, and pCTU3 of $C$. turicensis z3032. Plasmid group 1: pSP291-1, pESA3, and pCTU1; plasmid group 2: pSP291-2 and pCTU3.

Table S6 | Numerical data for all 20 PM plates of $C$. sakazakii SP291 and C. sakazakii ATCC BAA-894, along with the phenotype differences (greater than $20,000 \pm 1,800$ unit) generated by Omnilog ${ }^{\circledR}$ software.

Table S7 | Genes assigned to defined bacterial sub-systems and their distribution among these functional categories for $C$. sakazakii SP291 along with other three completed genome, $C$. sakazakii ATCC BAA-894, $C$. sakazakii ES15, and C. turicensis z3032.

Table S8 | Genome annotation: Carbohydrate metabolism of $C$. sakazakii SP291 and C. sakazakii ATCC BAA-894.

Table S9 | Genome annotation: Phosphorus metabolism of $C$. sakazakii SP291 and C. sakazakii ATCC BAA-894.

Table S10 | Genome annotation: Sulfur metabolism of $C$. sakazakii SP291 and C. sakazakii ATCC BAA-894.

Table S11 | Iron acquisition systems identified in the chromosome of $C$. sakazakii SP291.

ready-to-eat foods other than infant formula. Int. J. Food Microbiol. 136, 189-192. doi: 10.1016/j.ijfoodmicro.2009.04.009

Beuchat, L. R., Komitopoulou, E., Beckers, H., Betts, R. P., Bourdichon, F., Fanning, S., et al. (2013). Low-water activity foods: increased concern as vehicles of foodborne pathogens. J. Food Prot.76, 150-172. doi: 10.4315/0362-028X.JFP-12-211

Bowen, A. B., and Braden, C. R. (2006). Invasive Enterobacter sakazakii disease in infants. Emerg. Infect. Dis. 12, 1185-1189. doi: 10.3201/eid1708.051509
Brown, J. M., and Shaw, K. J. (2003). A novel family of Escherichia coli toxin-antitoxin gene pairs. J. Bacteriol. 185, 6600-6608. doi: 10.1128/JB.185.22.6600-6608.2003

Cairney, J., Booth, I. R., and Higgins, C. F. (1985). Osmoregulation of gene expression in Salmonella typhimurium: proU encodes an osmotically induced betaine transport system. J. Bacteriol. 164, 1224-1232.

Carranza, P., Grunau, A., Schneider T., Hartmann, I., Lehner, A. Stephan, R., et al. (2010). A gel-free quantitative proteomics approach to investigate temperature 
adaptation of the food-borne pathogen Cronobacter turicensis 3032. Proteomics 10, 3248-3261. doi: 10.1002/pmic. 200900460

Carver, T., Thomson, N., Bleasby, A., Berriman, M., and Parkhill, J. (2009). DNAPlotter: circular and linear interactive genome visualization. Bioinformatics 25, 119-120. doi: 10.1093/bioinformatics/btn578

Chandra, R., Bharagava, R. N., Kapley, A., and Purohit, H. J. (2011). Bacterial diversity, organic pollutants and their metabolites in two aeration lagoons of common effluent treatment plant (CETP) during the degradation and detoxification of tannery wastewater. Bioresour. Technol. 102, 2333-2341. doi: 10.1016/j.biortech.2010.10.087

Chang, C. H., Chiang, M. L., and Chou, C. C. (2010). The effect of heat shock on the response of Cronobacter sakazakii to subsequent lethal stresses. Foodborne Pathog. Dis. 7, 71-76. doi: 10.1089/fpd.2009.0345

Chap, J., Jackson, P., Siqueira, R., Gaspar, N., Quintas, C., Park, J., et al. (2009). International survey of Cronobacter sakazakii and other Cronobacter spp. in follow up formulas and infant foods. Int. J. Food Microbiol. 136, 185-188. doi: 10.1016/j.ijfoodmicro.2009.08.005

Checroun, C., and Gutierrez, C. (2004). Sigma(s)-dependent regulation of yehZYXW, which encodes a putative osmoprotectant ABC transporter of Escherichia coli. FEMS Microbiol. Lett. 236, 221-226. doi: 10.1016/ j.femsle.2004.05.046

Chen, Y., Strain, E. A., Allard, M., and Brown, E. W. (2011). Genome sequence of Cronobacter sakazakii E899, a strain associated with human illness. J. Bacteriol. 193:5861. doi: 10.1128/JB.05913-11

Chon, J. W., Song, K. Y., Kim, S. Y., Hyeon, J. Y., and Seo, K. H. (2012). Isolation and characterization of Cronobacter from desiccated foods in Korea. J. Food Sci. 77, M354-M358. doi: 10.1111/j.17503841.2012.02750.x

Cooney, S. (2012). A Sudy on the Epidemiology and Behavior of Selected Bacteria Colonizing a Podweed Infant Formula (PIF) Low Moisture Production Environment. $\mathrm{PhD}$ thesis, University College Dublin, 185.

Correia, F. F., D’Onofrio, A., Rejtar, T., Li, L., Karger, B. L., Makarova, K., et al. (2006). Kinase activity of overexpressed HipA is required for growth arrest and multidrug tolerance in Escherichia coli. J. Bacteriol. 188, 8360-8367. doi: 10.1128/JB.01237-06
Crosa, J. H., and Walsh, C. T. (2002). Genetics and assembly line enzymology of siderophore biosynthesis in bacteria. Microbiol. Mol. Biol. Rev. 66, 223-249. doi: 10.1128/MMBR.66.2.223-249.2002

Dancer, G. I., Mah, J. H., and Kang, D. H. (2009a). Influences of milk components on biofilm formation of Cronobacter spp. (Enterobacter sakazakii). Lett. Appl. Microbiol. 48, 718-725.

Dancer, G. I., Mah, J. H., Rhee, M. S., Hwang, I. G., and Kang, D. H. (2009b). Resistance of Enterobacter sakazakii (Cronobacter spp.) to environmental stresses. J. Appl. Microbiol. 107, 1606-1614. doi: 10.1111/j.1365-2672.2009.04347.x

Drudy, D., O’Rourke, M., Murphy, M., Mullane, N. R., O’Mahony, R., Kelly, L., et al. (2006). Characterization of a collection of Enterobacter sakazakii isolates from environmental and food sources. Int. J. Food Microbiol. 110, 127-134. doi: 10.1016/j.ijfoodmicro.2006.02.008

Dumen, E. (2010). Cronobacter sakazakii (Enterobacter sakazakii): only an infant problem. Kafkas Univ. Vet. Fak. Derg. 16, S171-S178.

El-Sharoud, W. M., O'Brien, S., Negredo, C., Iversen, C., Fanning, S., and Healy, B. (2009). Characterization of Cronobacter recovered from dried milk and related products. BMC Microbiol. 9:24. doi: 10.1186/1471-2180-9-24

Farmer, J. J. 3rd, Asbury, M. A., Hickman, F. W., and Brenner, D. J. (1980). Enterobacter sakazakii A new species of Enterobacteriaceae isolate from clinical specime. Int. J. Syst. Evol. Microbiol. 30, 569-584.

Feeney, A., and Sleator, R. D. (2011). An in silico analysis of osomotolerancec in the emerging gastrointestinal pathogen Cronobacter sakazakii. Bioeng. Bugs 2, 260-270. doi: 10.4161/bbug.2.5.17238

Finn, S., Handler, K., Condell, O., Colgan, A., Cooney, S., Hinton, J., et al. (2013). ProP is required for the survival of Salmonella Typhimurium desiccated on stainless steel. Appl. Environ. Microbiol. 79, 4376-4384. doi: 10.1128/AEM.00515-13

Franco, A. A., Hu, L., Grim, C. J., Gopinath, G., Sathyamoorthy, V., Jarvis, K. G., et al. (2011). Characterization of putative virulence genes on the related RepFIB plasmids harbored by Cronobacter spp. Appl. Environ. Microbiol. 77, 3255-3267. doi: 10.1128/AEM.03023-10

Friedemann, M. (2009). Epidemiology of invasive neonatal Cronobacter (Enterobacter sakazakii) infections. Eur. J. Clin. Microbiol. 28,
1297-1304. doi: 10.1007/s10096009-0779-4

Frossard, S. M., Khan, A. A., Warrick, E. C., Gately, J. M., Hanson, A. D., Oldham, M. L., et al. (2012). Identification of a third osmoprotectant transport system, the osmU system, in Salmonella enterica. J. Bacteriol. 194, 3861-3871. doi: 10.1128/JB.00495-12

Gajdosova, J., Benedikovicova, K., Kamodyova, N., Tothova, L., Kaclikova, E., Stuchlik, S., et al. (2011). Analysis of the DNA region mediating increased thermotolerance at 58 degrees $\mathrm{C}$ in Cronobacter spp. and other enterobacterial strains. Antonie Van Leeuwenhoek 100, 279-289. doi: 10.1007/s10482-011-9585-y

Gibson, D. L., White, A. P., Snyder, S. D., Martin, S., Heiss, C., Azadi, P. et al. (2006). Salmonella produces an O-antigen capsule regulated by AgfD and important for environmental persistence. J. Bacteriol. 188, 7722-7730. doi: 10.1128/ JB.00809-06

Goldman, E. and Green, L. H. (2009). Practical Handbook of Microbiology. London: CRC Press.

Gosney, M. A., Martin, M. V., Wright, A. E., and Gallagher, M. (2006). Enterobacter sakazakii in the mouths of stroke patients and its association with aspiration pneumonia. Eur. J. Intern. Med. 17, 185-188. doi: 10.1016/j.ejim.2005.11.010

Grim, C. J., Kothary, M. H., Gopinath, G., Jarvis, K. G., Beaubrun, J. J., McClelland, M., et al. (2012). Identification and characterization of Cronobacter iron acquisition systems. Appl. Environ. Microbiol. 78, 6035-6050. doi: 10.1128/AEM.01457-12

Grim, C. J., Kotewicz, M. L., Power, K., Pagotto, F., Gopinath, G., Mammel, M. K., et al. (2013). Pan genome analysis of the emerging foodborne pathogen Cronobacter spp. suggests a species-level bidirectional divergence driven by niche adaption. BMC Genomics. 14:366. doi: 10.1186/1471-2164-14-366

Gurtler, J. B., Kornacki, J. L., and Beuchat, L. R. (2005). Enterobacter sakazakii: a coliform of increased concern to infant health. Int. J. Food Microbiol. 104, 1-34. doi: 10.1016/j.ijfoodmicro.2005.02.013

Himelright, I., Harris, E., Lorch, V., Anderson, M., Jones, T., Craig, A., et al. (2002). Enterobacter sakazakii infections associated with the use of powdered infant formula - Tennessee, 2001. JAMA, 287, 2204-2205.

Hunter, C. J., Petrosyan, M., Ford, H. R., and Prasadarao, N. V.
(2008). Enterobacter sakazakii: an emerging pathogen in infants and neonates. Surg. Infect. 9, 533-539. doi: 10.1089/sur.2008.006

Iversen, C., Lehner, A., Mullane, N., Marugg, J., Fanning, S., Stephan, R., et al. (2007). Identification of "Cronobacter" spp. (Enterobacter sakazakii). J. Clin. Microbiol. 45, 3814-3816. doi: 10.1128/JCM.01026-07

Iversen, C., Mullane, N., McCardell, B., Tall, B. D., Lehner, A., Fanning, S. et al. (2008). Cronobacter gen. nov., a new genus to accommodate the biogroups of Enterobacter sakazakii, and proposal of Cronobacter sakazakii gen. nov., comb. nov., Cronobacter malonaticus sp. nov., Cronobacter turicensis sp. nov., Cronobacter muytjensii sp. nov., Cronobacter dublinensis sp. nov., Cronobacter genomospecies 1, and of three subspecies, Cronobacter dublinensis subsp. dublinensis subsp. nov., Cronobacter dublinensis subsp. lausannensis subsp. nov. and Cronobacter dublinensis subsp. lactaridi subsp. nov. Int. J. Syst. Evol. Microbiol. 58, 1442-1447. doi: 10.1099/ijs.0.65577-0

Iversen, C., Waddington, M., On, S. L., and Forsythe, S. (2004) Identification and phylogeny of Enterobacter sakazakii relative to Enterobacter and Citrobacter Species. J. Clin. Microbiol. 42, 5368-5370. doi: 10.1128/JCM.42.11.5368-5370.2004 Jaradat, Z. W., Ababneh, Q. O., Saadoun, I. M., Samara, N. A., and Rashdan, A. M. (2009). Isolation of Cronobacter spp. (formerly Enterobacter sakazakii) from infant food, herbs and environmental samples and the subsequent identification and confirmation of the isolates using biochemical, chromogenic assays, PCR and 16S rRNA sequencing. BMC Microbiol. 9:225. doi: 10.1186/1471-21809-225

Jarvis, K. G., Grim, C. J., Franco, A. A., Gopinath, G., Sathyamoorthy, V., Hu, L., et al. (2011). Molecular characterization of Cronobacter lipopolysaccharide O-antigen gene clusters and development of serotype-specific PCR assays. Appl. Environ. Microbiol. 77, 4017-4026. doi: 10.1128/AEM. 00162-11

Jarvis, K. G., Yan, Q. Q., Grim, C. J., Power, K. A., Franco, A. A., Hu, L., et al. (2013). Identification and characterization of five new molecular serogroups of Cronobacter spp. Foodborne Pathog. Dis. 10, 343-352. doi: 10.1089/fpd.2012.1344 
Joseph, S., Cetinkaya, E., Drahovska, H., Levican, A., Figueras, M. J., and Forsythe, S. J. (2011). Cronobacter condimenti sp. nov., isolated from spiced meat, and Cronobacter universalis sp. nov., a species designation for Cronobacter sp. genomospecies 1, recovered from a leg infection, water and food ingredients. Int. J. Syst. Evol. Microbiol. 62, 1277-1283. doi: 10.1099/ijs.0.032292-0

Joseph, S., Desai, P., Ji, Y. M., Cummings, C. A., Shih, R., Degoricija, L., et al. (2012). Comparative analysis of genome sequences covering the seven Cronobacter species. PLoS ONE 7:e49455. doi: 10.1371/journal.pone.0049455

Joseph, S. and Forsythe, S. J. (2012). Insight into the emergent bacterial pathogen Cronobacter spp., generated by multilocus sequence typing and analysis. Front. Microbiol. 3:397. doi: 10.3389/fmicb.2012.00397

Kim, K., Kim, K. P., Choi, J., Lim, J. A., Lee, J., Hwang, S., et al. (2010). Outer membrane proteins $\mathrm{A}(\mathrm{OmpA})$ and $\mathrm{X}(\mathrm{OmpX})$ are essential for basolateral invasion of Cronobacter sakazakii. Appl. Environ. Microbiol. 76, 5188-5198. doi: 10.1128/AEM.02498-09

Kucerova, E., Clifton, S. W., Xia, X. Q., Long, F., Porwollik, S., Fulton, L., et al. (2010). Genome sequence of Cronobacter sakazakii BAA-894 and comparative genomic hybridization analysis with other Cronobacter Species. PLOS ONE 5:e9556. doi: 10.1371/journal.pone.0009556

Lamark, T., Kaasen, I., Eshoo, M. W., Falkenberg, P., McDougall, J., and Strom, A. R. (1991). DNA sequence and analysis of the bet genes encoding the osmoregulatory choline - glycine betaine pathway of Escherichia coli. Mol. Microbiol. 5, 1049-1064. doi: 10.1111/j.13652958.1991.tb01877.x

Lee, J. H., Choi, Y., Shin, H., Lee, J., and Ryu, S. (2012). Complete genome sequence of Cronobacter sakazakii temperate bacteriophage phiES15. J. Virol. 86, 7713-7714. doi: 10.1128/JVI.01042-12

Lehner, A., Fricker-Feer, C., and Stephan, R. (2012). Identification of the recently described Cronobacter condimenti by a $r p o B$ based PCR system. J. Med. Microbiol. 67, 1034-1035. doi: 10.1099/jmm.0.042903-0

Lewis, K. (2000). Programmed death in bacteria. Microbiol. Mol. Biol. Rev. 64, 503-514

Mange, J. P., Stephan, R., Borel, N., Wild, P., Kim, K. S., Pospischil, A., et al. (2006). Adhesive properties of Enterobacter sakazakii to human epithelial and brain microvascular endothelial cells. BMC Microbiol. 6:58. doi: 10.1186/1471-2180-6-58

Maurelli, A. T. (2007). Black holes, antivirulence genes, and gene inactivation in the evolution of bacterial pathogens. FEMS Microbiol. Lett. 267, 1-8. doi: 10.1111/j.15746968.2006.00526.x

Miranda, C. D., Kehrenberg, C., Ulep, C., Schwarz, S., and Roberts, M. C. (2003). Diversity of tetracycline resistance genes in bacteria from chilean salmon farms. Antimicrob. Agents Chemother. 47, 883-888. doi: 10.1128/AAC.47.3.883-888.2003

Mullane, N., Healy, B., Meade, J., Whyte, P., Wall, P. G., and Fanning, S. (2008a). Dissemination of Cronobacter spp. (Enterobacter sakazakii) in a powdered milk protein manufacturing facility. Appl. Environ. Microbiol. 74, 5913-5917.

Mullane, N., O'Gaora, P., Nally, J. E., Iversen, C., Whyte, P., Wall, P. G., et al. (2008b). Molecular analysis of the Enterobacter sakazakii $\mathrm{O}$-antigen gene locus. Appl. Environ. Microbiol. 74, 3783-3794.

Mullane, N. R., Iversen, C., Healy, B. Walsh, C., Whyte, P., Wall, P. G., et al. (2007). Enterobacter sakazakii an emerging bacterial pathogen with implications for infant health. Minerva Pediatr. 59, 137-148.

Overbeek, R., Begley, T., Butler, R. M., Choudhuri, J. V., Chuang, H. Y., Cohoon, M., et al. (2005). The subsystems approach to genome annotation and its use in the project to annotate 1000 genomes. Nucleic Acids Res. 33, 5691-5702. doi: 10.1093/nar/gki866

Power, K. A., Yan, Q. Q., Fox, E. Cooney, S., and Fanning, S. (2013). Genome sequence of Cronobacter sakazakii SP291 - a persistent thermo-tolerant powdered infant formula factory-derived pathogen. Genome Announc. 1:e0008213. doi: 10.1128/genomeA.00082-13

Schmid, M., Iversen, C., Gontia I., Stephan, R., Hofmann, A., Hartmann, A., et al. (2009). Evidence for a plant-associated natural habitat for Cronobacter spp. Res. Microbiol. 160, 608-614. doi: 10.1016/j.resmic.2009.08.013

See, K. C., Than, H. A., and Tang, T. (2007). Enterobacter sakazakii bacteraemia with multiple splenic abscesses in a 75-year-old woman: a case report. Age Ageing 36, 595-596. doi: 10.1093/ageing/afm092

Serfiotis-Mitsa, D., Herbert, A. P., Roberts, G. A., Soares, D. C., White, J. H., Blakely, G. W., et al. (2010). The structure of the KlcA and ArdB proteins reveals a novel fold and antirestriction activity against
Type I DNA restriction systems in vivo but not in vitro. Nucleic Acids Res. 38, 1723-1737. doi 10.1093/nar/gkp1144

Shaker, R. R., Osaili, T. M., Abu AlHasan, A. S., Ayyash, M. M., and Forsythe, S. J. (2008). Effect of desiccation, starvation, heat, and cold stresses on the thermal resistance of Enterobacter sakazakii in rehydrated infant milk formula. J. Food Sci. 73, M354-M359. doi: 10.1111/ j.1750-3841.2008.00880.x

Shin, H., Lee, J. H., Choi, Y., and Ryu, S. (2012). Complete genome sequence of the opportunistic food-borne pathogen Cronobacter sakazaki ES15. J. Bacteriol. 194, 4438-4439. doi: 10.1128/JB.00841-12

Shin, J. H., Oh, S. Y., Kim, S. J., and Roe, J. H. (2007). The zincresponsive regulator Zur controls a zinc uptake system and some ribosomal proteins in Streptomyces coelicolor A3(2). J. Bacteriol. 189, 4070-4077. doi: 10.1128/JB.0185106

Sivamaruthi, B. S., Ganguli, A., Kumar, M., Bhaviya, S., Pandian, S. K. and Balamurugan, K. (2011) Caenorhabditis elegans as a mode for studying Cronobacter sakazaki ATCC BAA-894 pathogenesis. J. Basic Microbiol. 51, 540-549. doi 10.1002/jobm.201000377

Stephan, R., Lehner, A., Tischler, P. and Rattei, T. (2011). Complete genome sequence of Cronobacter turicensis LMG 23827, a foodborne pathogen causing deaths in neonates. J. Bacteriol. 193, 309-310. doi: 10.1128/JB.01162-10

Stock, I., and Wiedemann, B. (2002). Natural antibiotic susceptibility of Enterobacter amnigenus, Enterobacter cancerogenus, Enterobacter gergoviae and Enterobacter sakazakii strains. Clin. Microbiol. Infect. 8, 564-578. doi 10.1046/j.1469-0691.2002.00413.x

Stoop, B., Lehner, A., Iversen, C. Fanning, S., and Stephan, R. (2009). Development and evaluation of $r p o B$ based PCR systems to differentiate the six proposed species within the genus Cronobacter. Int. J. Food Microbiol. 136, 165-168. doi: 10.1016/j.iffoodmicro.2009.04.023

Tsai, H. Y., Liao, C. H., Huang, Y. T., Lee, P. I., and Hsueh, P. R. (2013). Cronobacter infection not from infant formula, Taiwan. Emerg. Infect. Dis. 19, 1-3. doi: 10.3201/eid1901.120774

Tschowri, N., Busse, S., and Hengge, R. (2009). The BLUF-EAL protein $\mathrm{YcgF}$ acts as a direct antirepressor in a blue-light response of Escherichia coli. Genes Dev. 23 522-534. doi: 10.1101/gad.499409
Walsh, D., Molloy, C., Iversen, C., Carroll, J., Cagney, C., Fanning, S., et al. (2011). Survival characteristics of environmental and clinically derived strains of Cronobacter sakazakii in infant milk formula (IMF) and ingredients. J. Appl. Microbiol. 110, 697-703. doi: 10.1111/j.1365-2672.2010.04921.x

Wang, I. N., Smith, D. L., and Young, R. (2000). Holins: the protein clocks of bacteriophage infections. Annu. Rev. Microbiol. 54, 799-825. doi: 10.1146/annurev.micro.54.1.799

Williams, T. L., Monday, S. R., EdelsonMammel, S., Buchanan, R., and Musser, S. M. (2005). A topdown proteomics approach for differentiating thermal resistant strains of Enterobacter sakazakii. Proteomics 5, 4161-4169. doi: 10.1002/pmic.200401263

Yan, Q. Q., Condell, O., Power, K., Butler, F., Tall, B. D., and Fanning, S. (2012). Cronobacter species (formerly known as Enterobacter sakazakii) in powdered infant formula: a review of our current understanding of the biology of this bacterium. J. Appl. Microbiol. 113, 1-15. doi: 10.1111/j.13652672.2012.05281.x

Conflict of Interest Statement: The authors declare that the research was conducted in the absence of any commercial or financial relationships that could be construed as a potential conflict of interest.

Received: 22 March 2013; accepted: 13 August 2013; published online: 02 September 2013.

Citation: Yan QQ, Power KA, Cooney S, Fox E, Gopinath GR, Grim CJ, Tall BD, McCusker MP and Fanning S (2013) Complete genome sequence and phenotype microarray analysis of Cronobacter sakazakii SP291: a persistent isolate cultured from a powdered infant formula production facility. Front. Microbiol. 4:256. doi: 10.3389/fmicb.2013.00256

This article was submitted to Food Microbiology, a section of the journal Frontiers in Microbiology.

Copyright (๑) 2013 Yan, Power, Cooney, Fox, Gopinath, Grim, Tall, McCusker and Fanning. This is an open-access article distributed under the terms of the Creative Commons Attribution License (CC BY). The use, distribution or reproduction in other forums is permitted, provided the original author(s) or licensor are credited and that the original publication in this journal is cited, in accordance with accepted academic practice. No use, distribution or reproduction is permitted which does not comply with these terms. 


\section{APPENDIX}

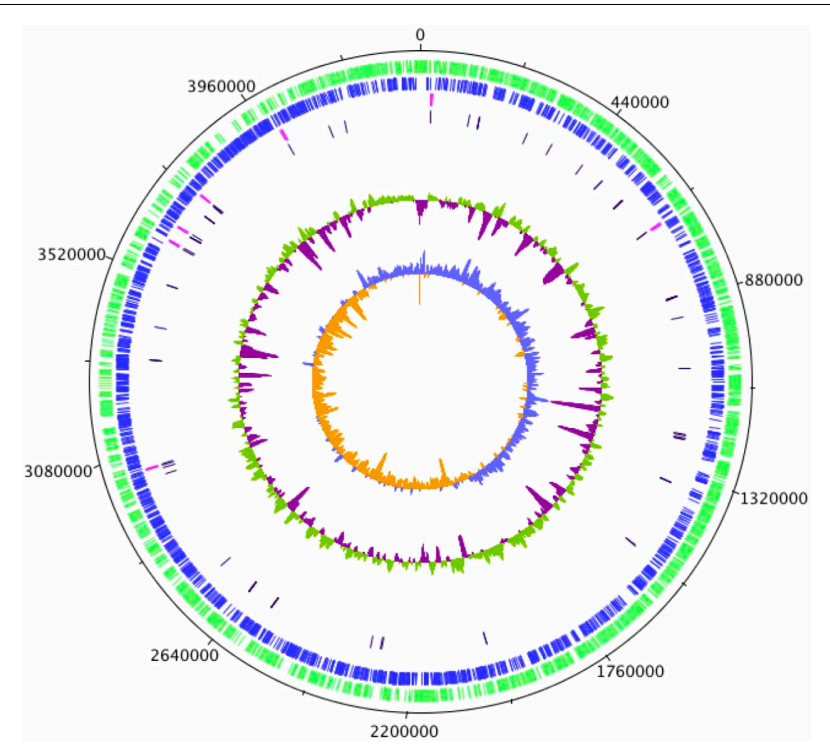

FIGURE A1 | Circular representation of the C. sakazakii SP291 genome. The first circle represents the scale in kilobases starting with the origin of replication at position 0 . The second circle shows the distribution of CDS (Goldman and Green, 2009) in forward strand. The third circle indicates the distribution of CDS (blue) in reverse strand. rRNA operons are colored in red on the fourth circle. tRNA operons are colored in purple on the fifth circle. The sixth circle indicates the deviation of the GC content average, with values greater than zero in green and those less than zero in purple. The innermost circle displays the GC skew ([G+C]/[G-C]), with values greater than zero in light blue and those less than zero in orange. The figure was generated using DNAPlotter (Carver et al., 2009).

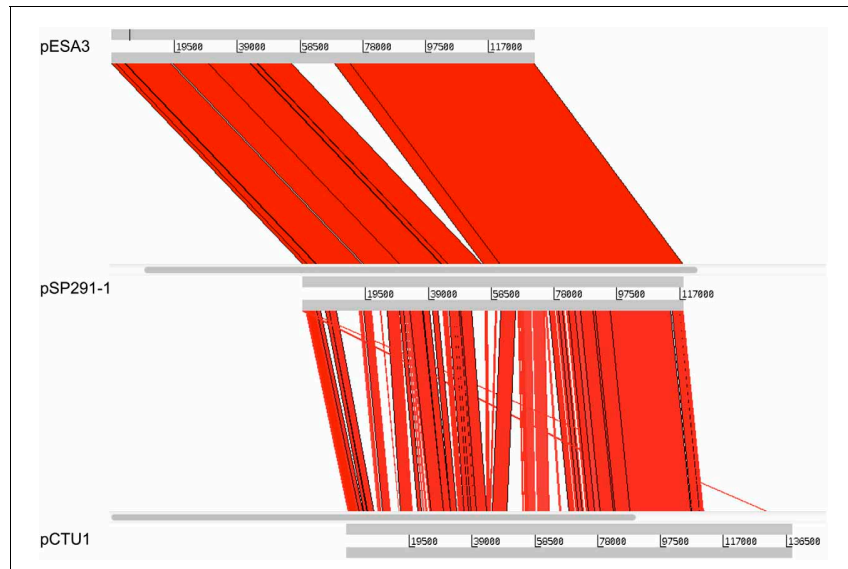

FIGURE A2 | Comparision of plasmid group 1 (pESA3, pSP291-1, and pCTU1) using Artemis comparison tool (ACT).

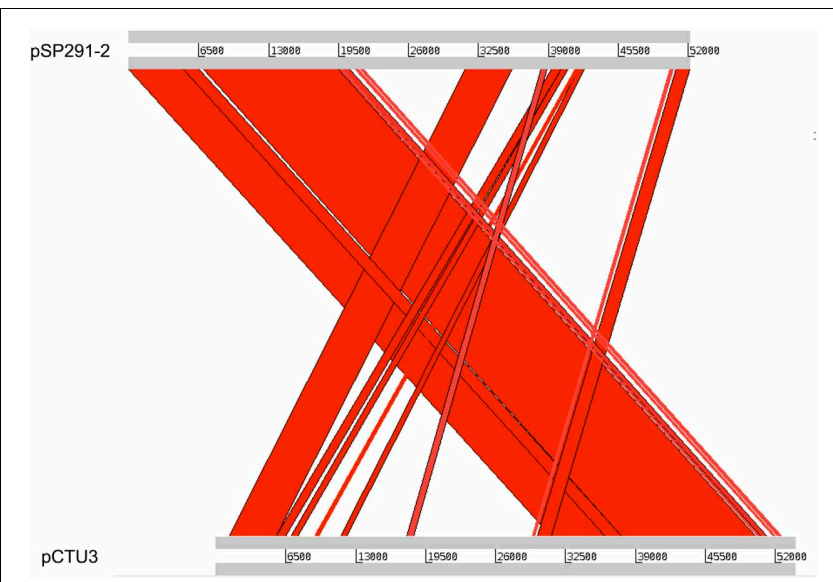

FIGURE A3 | Comparision of plasmid group 2 (pSP291-2 and pCTU3) using Artemis comparison tool (ACT). 